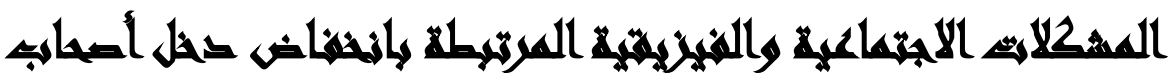

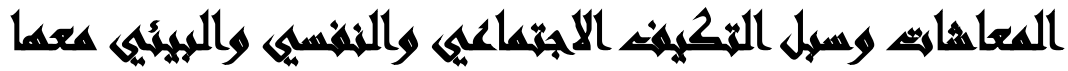

\section{[0]}

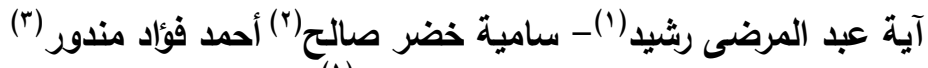

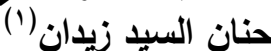

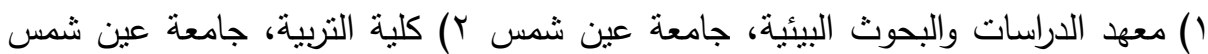

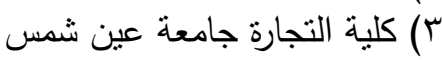

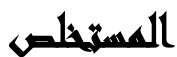

هدفت الدراسة إلي التحقق من المشكلات الاجتماعية والفيزيقية المرتبطة بانخفاض دخل

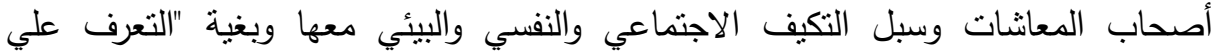

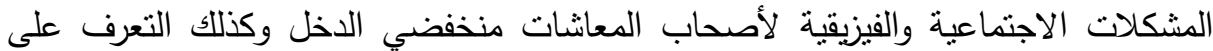

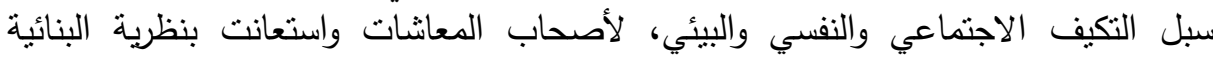

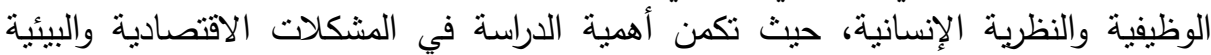

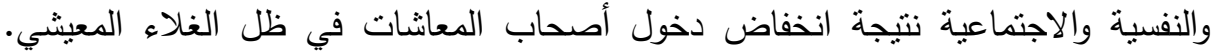

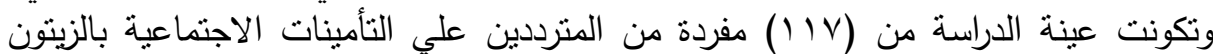

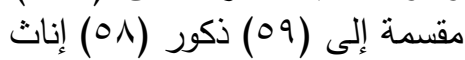

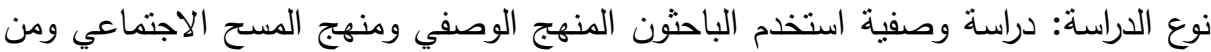
الأدوات استمارة استبيان للمشكلات الاجتماعية والفيزيقية إعداد الباحثون، التكيف الاجتماعي الاعتي

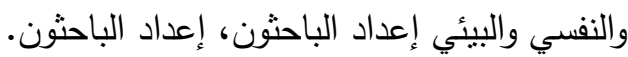
توصلت الاراسة إلى عدد من النتائج أهمها:

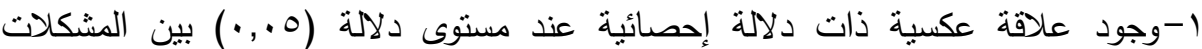

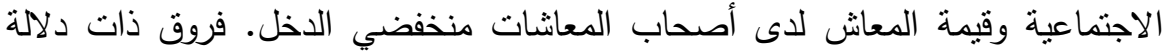

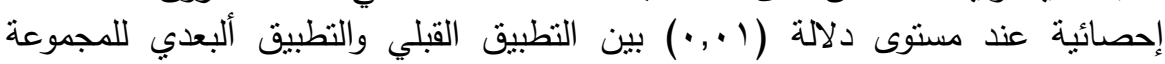

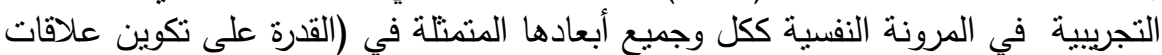

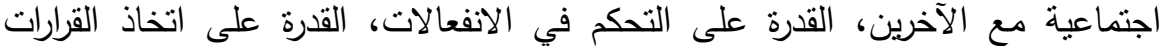
والتخطيط لحل المشكلات) لصاتح الآنسين التطبيق ألبعدي والحياة.

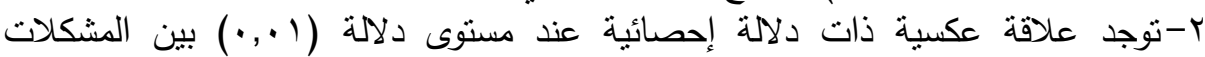

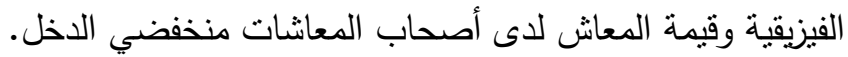

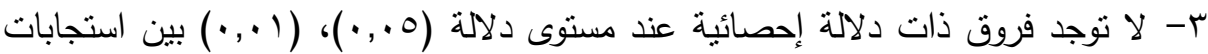

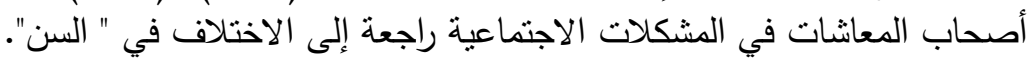


1-اهتمام المسئولون بهذه الثئريحة من خلال تقديم المساعدات والمعونة لهم في شتى مجالات الحياة. r-التصدي من قبل الوزارات المعنية ومؤسسات المجتمع المدني والأسر لمشكلات المسنين وتوفير الحلول العملية الملائمة لها. العان. r-التوسع في إنشاء دور لرعاية المعادية المسنين حتى تتكفل بالمسن الذي يعانى بعدم وجود مأوى له

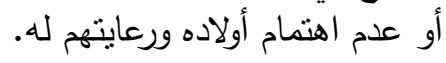

\section{Maxall}

من البديهي أن أي مجتمع يود أن يساير ركب التقام عليه أن يوجه اهنمامه إلى الموارد

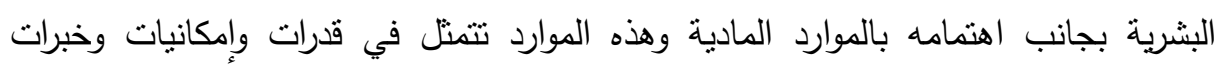

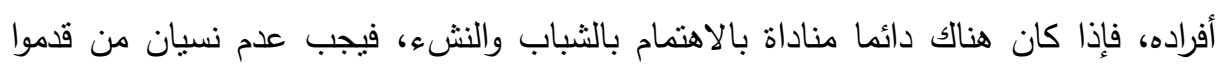

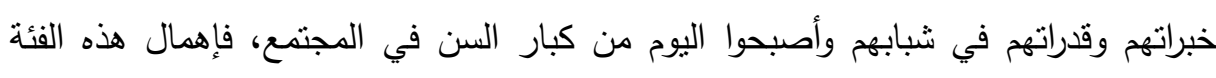

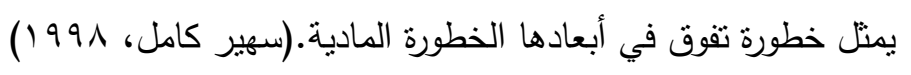
إن النقدم في الطب أدى إلى زيادة متوسط عمر الإنسان مما أدى إلى زيادة عدد الداديه

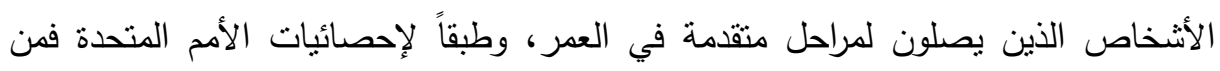

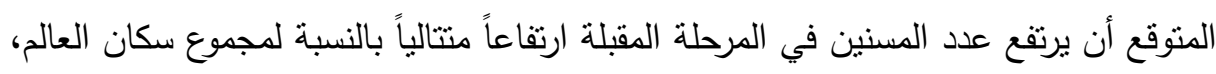

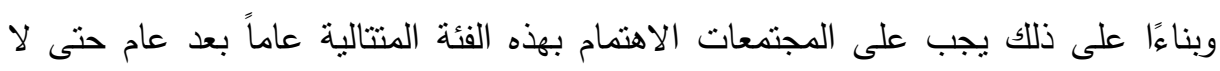

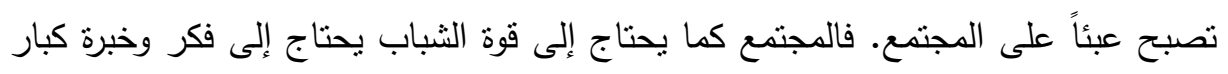

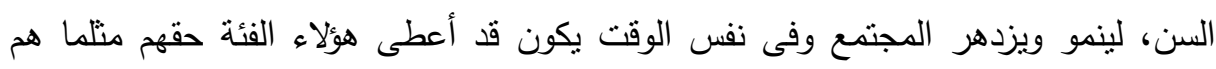

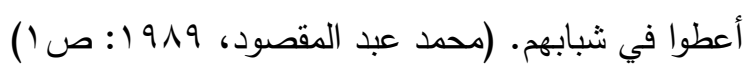

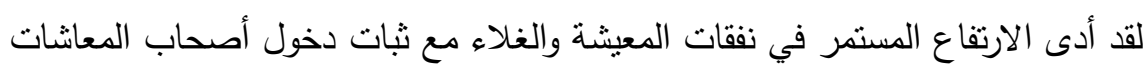

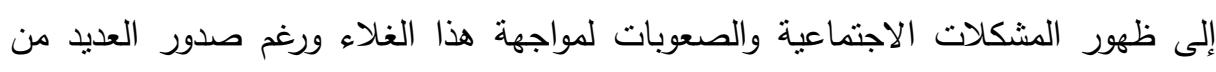

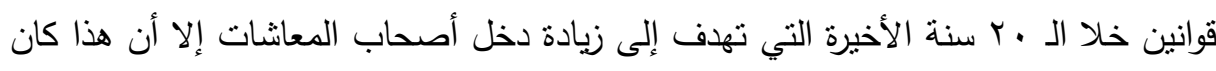

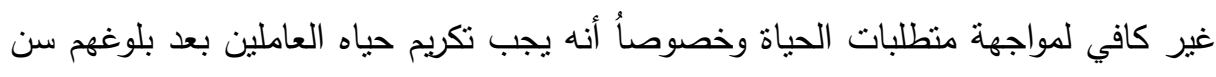

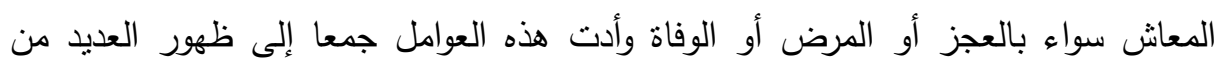

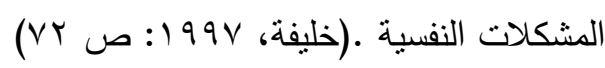


يواجه أصحاب المعانشات في هذه المرحلة من مشكلات اجتماعية ونفسية، وأما الجوانب

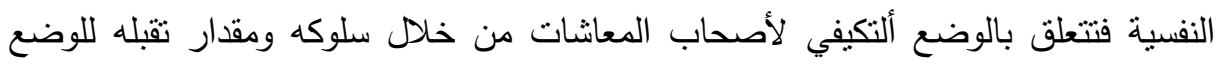
الذي يعيش فيه، وأما النواحي الاجتماعية فتعبر عن أدوار الأفراد أثناء تفاعلهم مع الآخرين لإني في المجتمع الذي يعيشون فيه(Woodruff-Pak,1997).

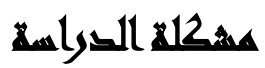

يعانى أصحاب المعانشات بصفة عامة في هذه المرحلة العمرية التي تمثل إحدى مراحل

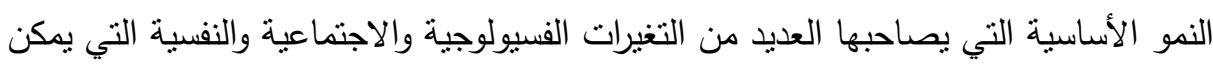

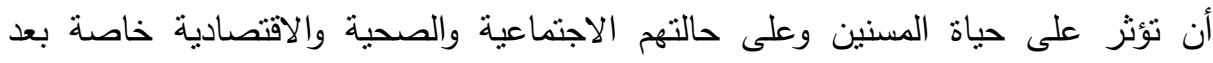

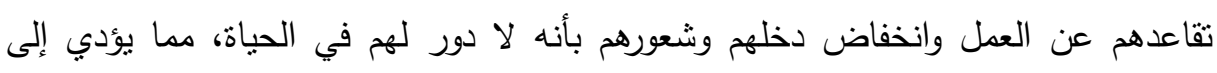
العديد من المشكلات المؤثرة على حياة أصحاب المعاشات، وأوضح الجهاز المركزي للتعبئة

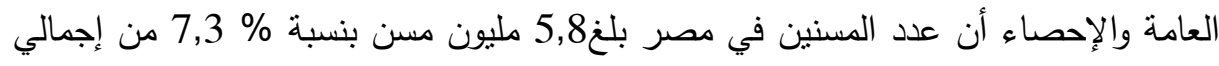

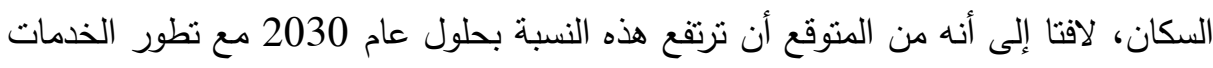
الصحية، ( مجلة الأخبار المصورة: 2011 ).

ومع هذا الارتفاع في منوسط الأعمار أخذت الفترة الحياتية في مرحلة ما بعد التقاعد

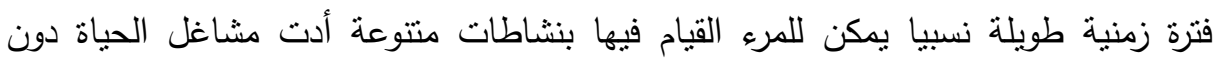
تحقيقها في السابق كالرحلات وتتمية الهوايات المتتاسبة مع السن والتقرغ للعلاقات الاجتماعية

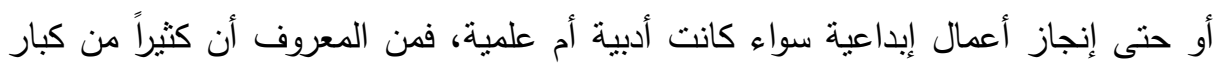

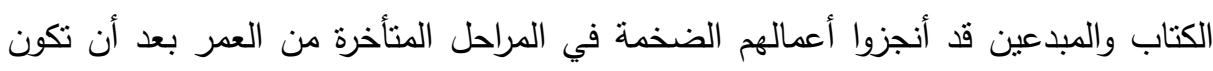
الخبرة والمعرفة قد نضجت وأصبحت في ذروتها (رضوان: 2011).

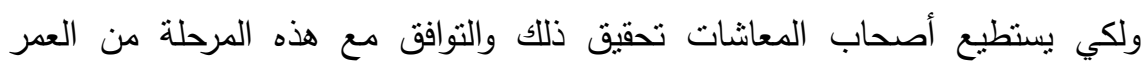
والاستفادة منها فهم بحاجة إلى الدعم المادي وغير المادي إثباع ذللك، ونتيجة لقلة الدراسات

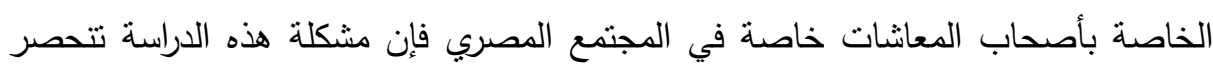

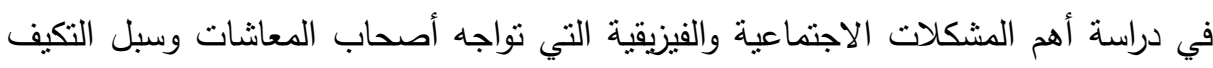

$$
\text { المجلد السادس والأربعون، الجزء الثاني، يونيه } 9 \text { 1 ـ ب }
$$


النفسي والبيئي لهذه المشكلات سعياً للوصول لبعض التوصيات المساهمة في حل هذه المشكلات.

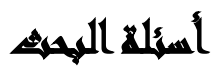

1-ما مدى وجود علاقة بين المشكلات الاجتماعية وقيمة المعاش لدى أصحاب المعاشـات

المنخفضة ؟

r- ما مدى قدرة أصحاب المعانثات منخفضي الدخل على التكيف الاجتماعي؟ r-ما الآليات التي يستفيد بها منخفضي الاخل في تحقيق التكيف الاجتماعي؟

\section{أهمهي التوراسة}

تكمن أهمية الدراسة في تتاولها لموضوع على قدر كبير من الأهمية لأنه يمنل حياة فئة

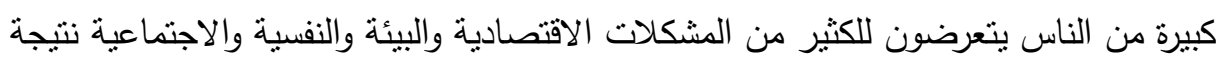

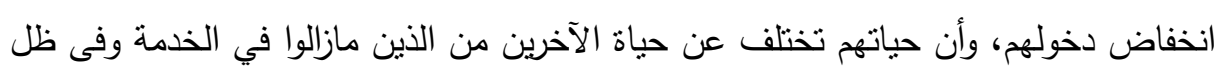
الغلاء المعيشي، وأن معظمهم من المسنين. أهمية النظرية: تتمثل في الإطار النظري وعرض موضوعاء المعات البحث:

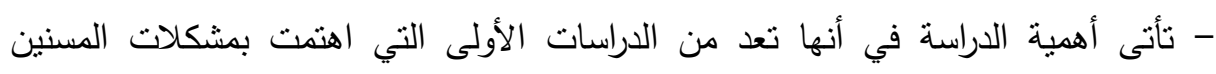

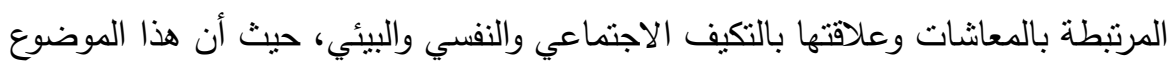

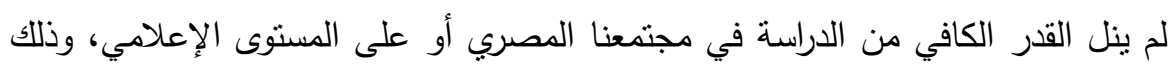
على حد علم الباحثة. - تساعد هذه الدراسة في فتح طريق إرشادي للأخصائيين والمرشدين في التعامل مع هذه الفئة وإيجاد حلول لمشكلاتهم ومساعدتهم على تحقيق التكيف النفسي والاجتماعي والبيئي لهم.

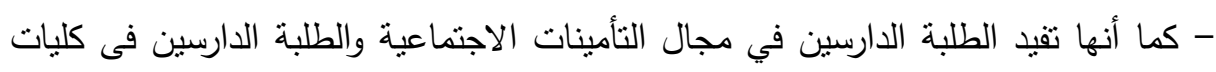

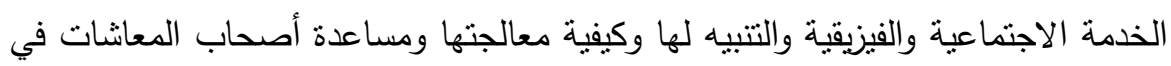
وجود بدائل لتحسين دخولهم. 


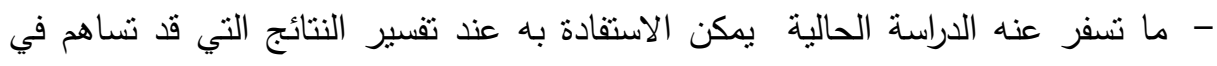
تزويد الجهات صاحبة القرار في الإمداد ببيانات عريضة تقيدها عند وضع إستراتيجية بندانه وطنية عريضة لرعاية المسنين في مصر على أسس علمية سليمة.

- تقدم صورة حقيقية عن انخفاض دخل أصحاب المعاشات ومشكلاتهم الاجتماعية والفيزيقية وكيفية التكيف الاجتماعي والبيئي والنفسي.

- توفير الأدوات والمقاييس التي تسهم في التعرف على الضغوط والتوترات النفسية والصحية

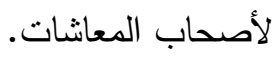

- توفير برامج ووضع خطه التعامل مع أصحاب المعانشات في توفير الرعاية الصحية والاجنماعية. - توفير العوامل الفيزيقية التي تساعدهم على مواصلة الحياة.

\section{أهساهيت الصوراسة}

ا. التعرف على المشكلات الاجتماعية والفيزيقية التي تواجه أصحاب المعاثشات منخفضي

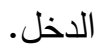

r. الكثف عن كيفية تكيف أصحاب المعانشات منخفضي الدخل مع مشكلاتهم الاجتماعية والفيزيقية. r. التعرف على العلاقة بين انخفاض دخل أصحاب المعاشات ومشكلاتهم الاجتماعية والفيزيقية.

\section{مهذاهيه الصراسمة}

1-المشكـلات الاجتماعية (Social problems): المشكلة في اللغة مشنقة من الفعل

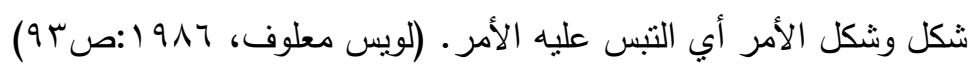

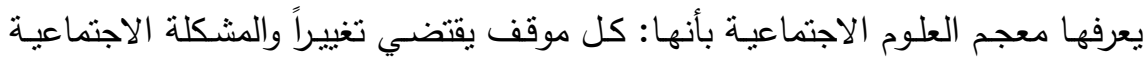

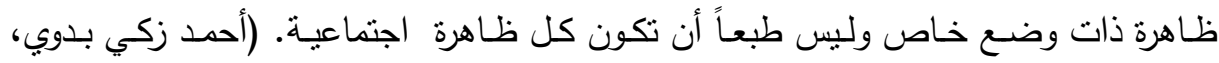




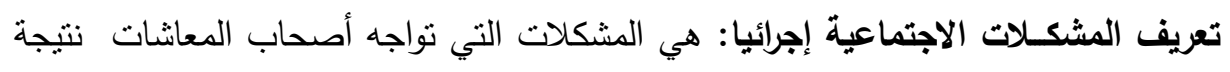

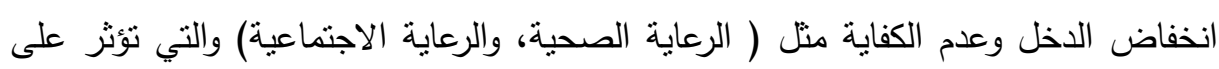
ارتباطهم بأفراد أسرتهم والآخرين.

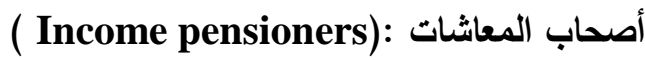

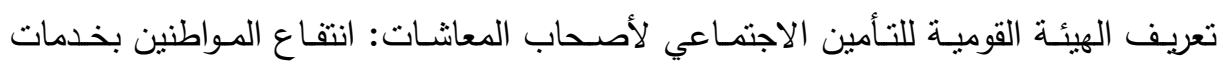

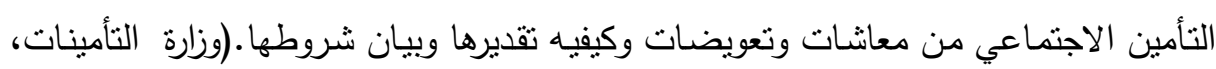
( r.... تعريف أصحاب المعاثات إجرائياً: هم أولئك الأفراد الذين ينقاضون معاثـات بثكل شهري

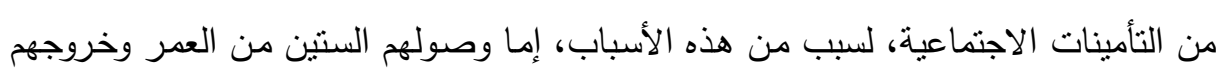

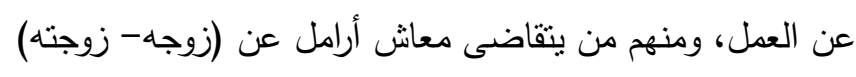
r-التكيف الاجتمـاعي ( A daptation Social

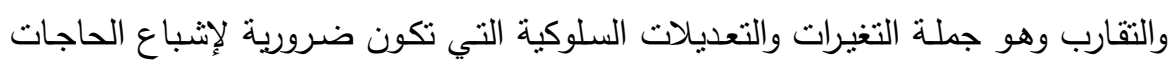

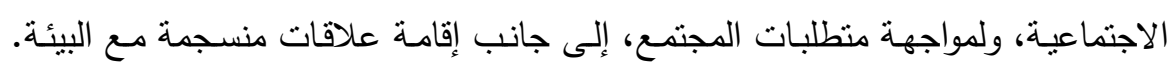

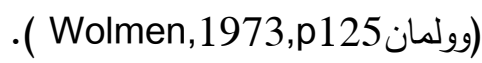

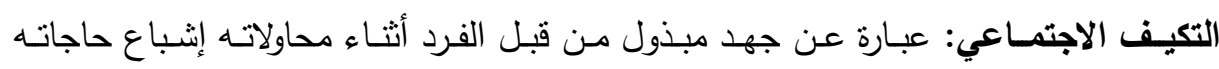

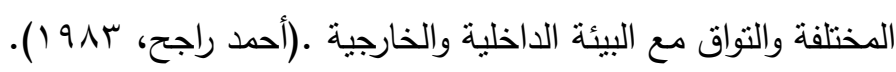

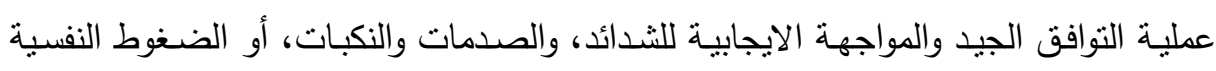

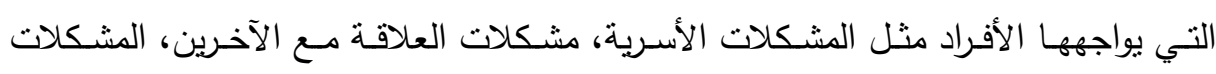
الصحية الخطيرة، ضغوط العمل والهشكلات المالية.

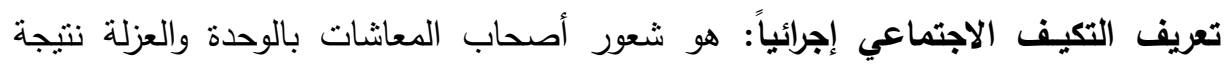
انفصال الأبناء عنهم وانثغالهم بحياتهم الخاصة. ץ-التكيف النفسي:( A daptation psychological): هو أساس تكامل الثخصية

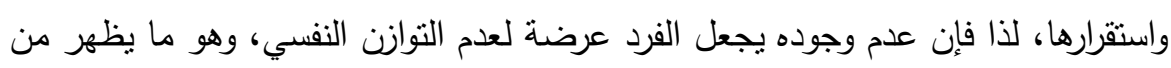

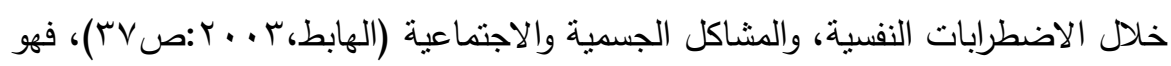

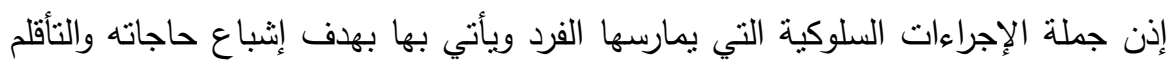
106

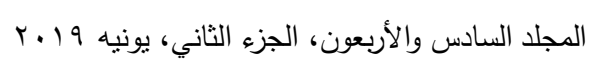


مع ظروف معينة في بيئتي الفرد الذاتية الداخلية (بناءه النفسي) والخارجية (الطبيعية

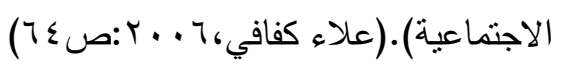

- تعريف التكيف النفسي إجرائياً: عدم قدرة المسن على إثباع حاجاته ودوافعه الداخلية في الأسرة وعدم الثعور بالرضا عن نفسه

ع - التكيف البيئي: صورة فقد عرف على مستوى الأفراد أو الأشخاص أنه محاولات الفرد

لتحقيق نوع من العلاقات الثابتة والمرضية مع البيئة (Gordon, 1963, P.10) - تعريف التكيف البيئي إجرائياً: عدم التكيف للخدمات الأساسية والمشكلات البيئية منل:

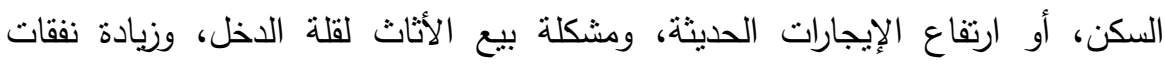
المعيشة، أو سوء التهوية داخل المساكن الضيقة، وضعف الإيخارات الإضاءة.

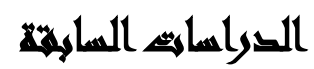

تمثلت الاراسات السابقة في محورين:

المحور الأول: الاراسات التي تناولت مشكلات أصحاب المعاشـات (المسنين)

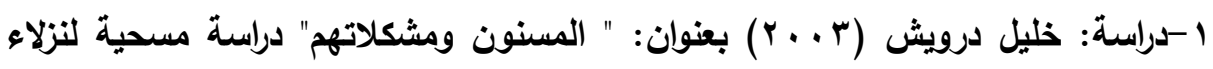

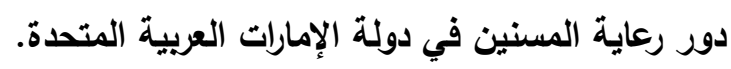

هدفت الدراسة: التعرف على الأسباب التي تؤدي إلى تحويل المسنين إلى دور الرعابل الرعاية، وكذلك التعرف على المشكلات التي يعانون منها من وجهة نظرهم. عينة الدراسة: تكونت عينة الدراسة من جميع المسنين المقيمين في دور الرعاية في دولة

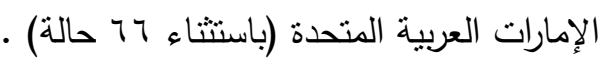
نتائج الدراسة: عجز المسنين عن خدمة أنفسهم بأنفسه وعزلتهم عن الآخرين هو من أقوى

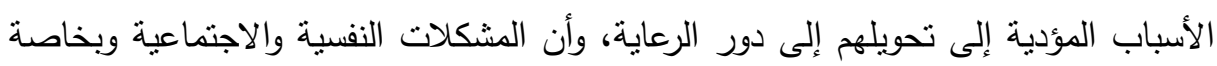

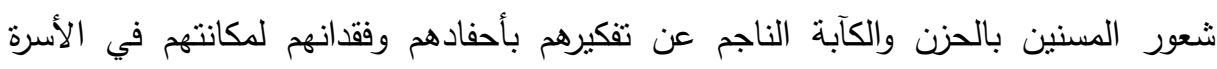

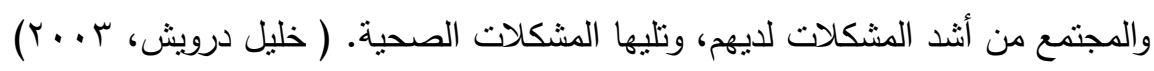


r-دراسة ياسمين عتيبة (·1+r) بغنوان: المشكلات التي يواجهها كبار السن في ظل بعض الثقافات الفرعية بريف محافظة كفر الثيخ.

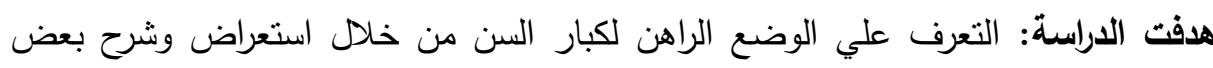

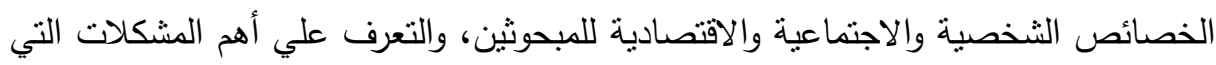

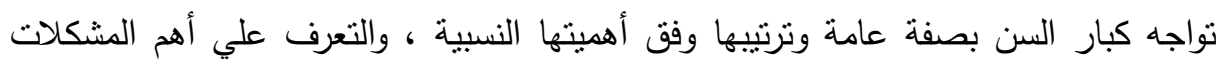

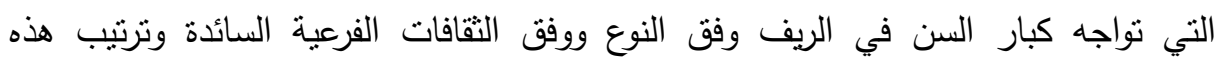

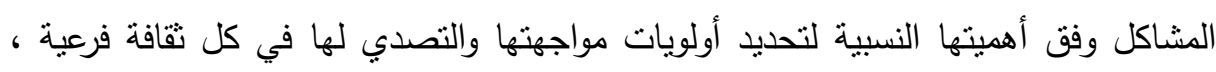

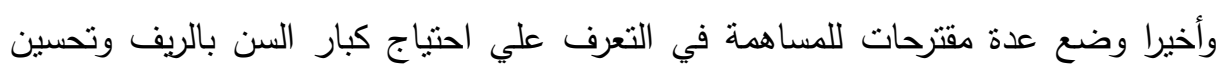
أوضاعهم في بعض نواحي الحياة.

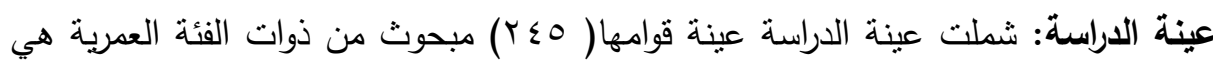

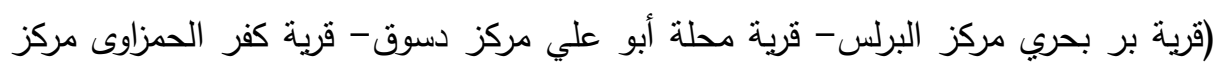

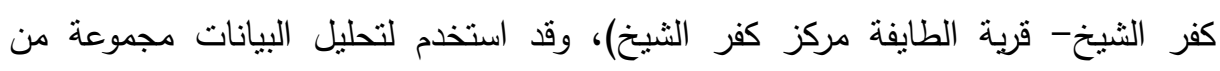

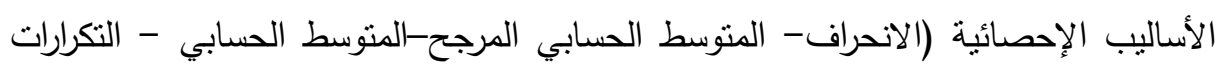
والنسب المئوية- - معامل ثبات كرونباخ " ألفا".

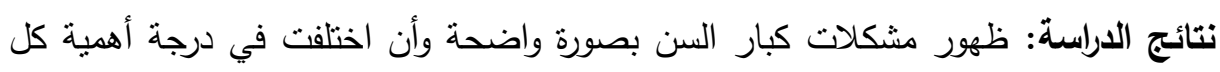

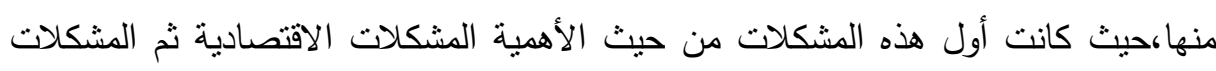

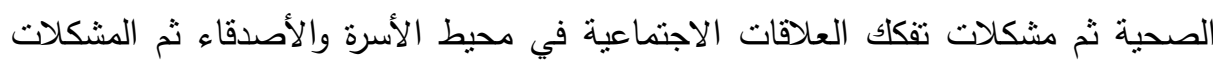

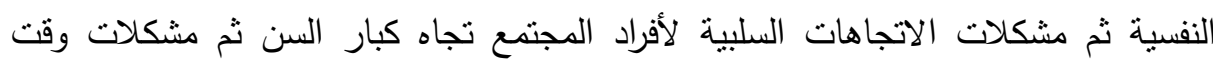

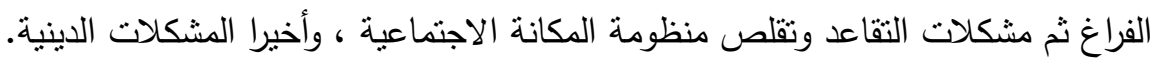

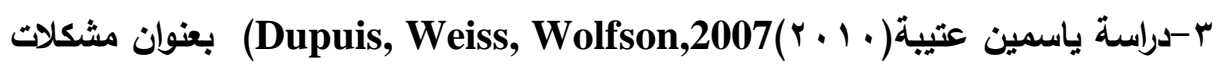

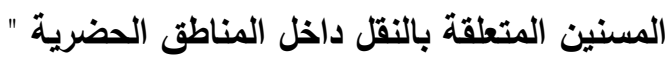

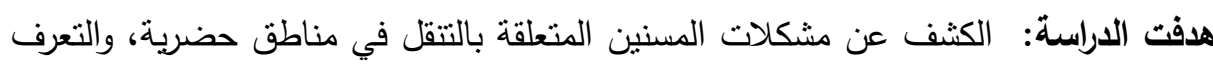
على الاحتياجات غير الملباة لليهم.

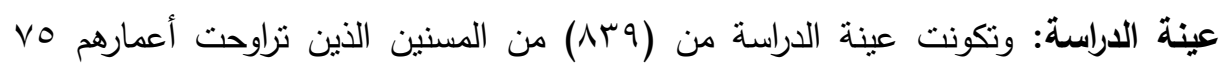

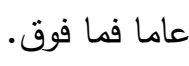


نتائج الاراسة: أن مشكلات التتقل هي مسألة هامة نواجه كبار السن وخاصة النساء،

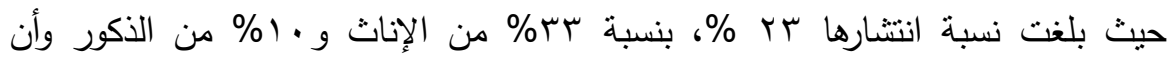

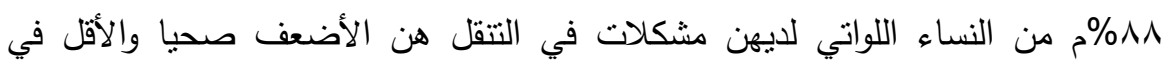

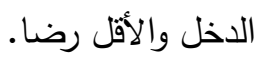

)(Dupuis, Weiss, Wolfson, 2007 المحسور الثـاني: دراسات تناولت التكيف النفسي والاجتماعي والبيئي: سوف يتتاول في هذا صورة الذات من خلال عرض(10) دراسات ميدانية حول المعاقين

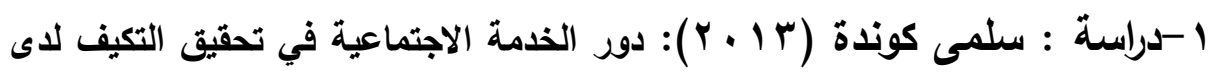

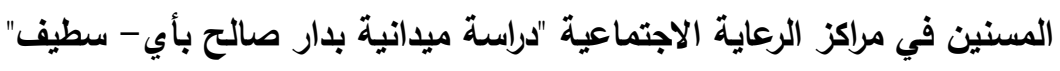

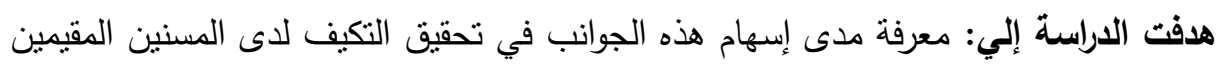
بمراكز الرعاية الاجتماعية والتعرف على ملائمة مراكز الرعاية الاجتماعية لبرامج الخدمة التهائ الاجنماعية وإمكانية تلبيته لاحتياجات المسنين.

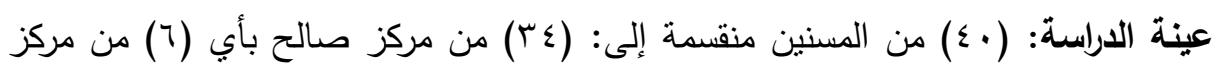
بوعقال. أداوت الدراسة: تتمثل في (استمارة استبيان- برنامج خدمة اجتماعية- دليل المقابلة والملاحظة).

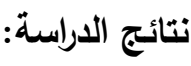
- برامج الخدمة الاجتماعية ومقدميها بمركز الرعاية يسهمون في تحقيق التكيف لدى المسنين المقيمين به. - الخدمة الاجتماعية تسهم في تحقيق التكيف لديهم.(سلمى كوندة: 1 ا ب ) 
Y - دراسة سمية جميل عوض(Y V P r Y): أثر برنامج تدريبي لمساعدة كبار السن في الأردن على التكيف الإيجابي مع مشكلاتهم. هدفت الدراسة: الكثف عن أثر برنامج تدريبي لمساعدة كبار السن في الأردن، والتعرف على ملى مئك التكيف الإيجابي مع مشكلاتهم. عينة الاراسة: ( • ع) سيدة من كبار السن مقسمة إلى قسمين:

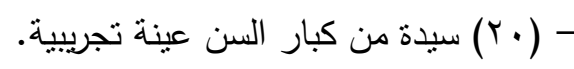

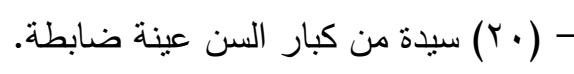
أدوات الدراسة: تتمثل في مقياس التكيف - برنامج تدريبي لمساعدة كبار السن.

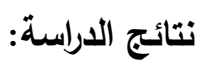
- وجود أثز للبرنامج التدريبي المستخدم في مساعدة كبار السن على التكيف الإيجابي.

- وجود أثز فاعل لممارسة استراتيجيات التكيف ضمن مجال التعبير عن المشاعر . r-راسة (Alexopoles et al., 2003) أثر طريقة حل المشكلات وطريقة علاج الداعم في تكيف مجموعة من كبار السن يعانون من اضطرابات وظيفية ولديهم اكتئاب. هدفت الاراسة: لتعرف علي اضطرابات الوظيفية.

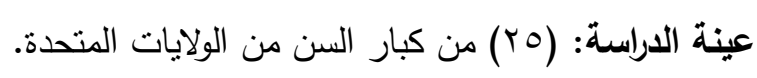
أدوات الدراسة: استمارة استبيان. نتائج الدراسة: وجدت الدراسة أن طريقة حل المشكلات كانت أكثر فاعلية من طريقة العلاج الداعم في مساعدة كبار السن على التكيف مع مشاكلهم، التخفيف من الثعور بالاكتئاب. .(Alexopoles et al., 2003) خلاصة الاراسات السابقة: - اهتمت دراسات المحور الأول المرتبط المشكلات الاجتماعية لكبار السن حيث تتاولت المشكلات الاجتماعية بصفة عامة للمسنين بصفة خاصة.

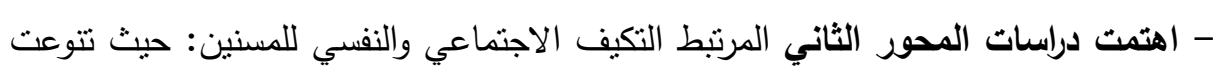

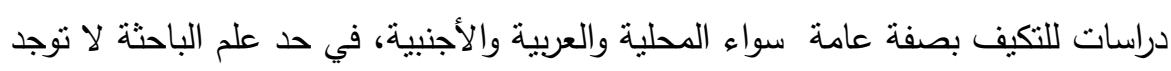
دراسات نطرقت للتكيف النفسي والاجتماعي والبيئي لأصحاب المعانشات. 
أما عن الأطر النظرية التي اعتمدت عليها الدراسات فكان التركيز على العديد من النظريات

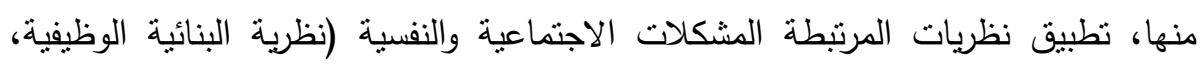

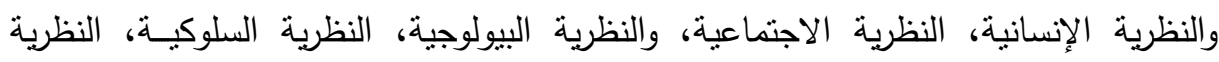
البيولوجيا الطبية) في معظم دراسات التكيف النفسي والاجتماعي والبيئي، وتطبيق نظريات ولنيات (،نظرية التحليل النفسي، النظرية البيولوجيا الطبية النظرية الإنسانية) واستفادت الباحثة من ولنيات

بعض هذه النظريات في دراستها. - أما عن الأطر منهجية فمعظم الدراسات ركزت على مناهج عدة منها:المناهج الوصفية، المنهج الكمي، المنهج المقارن، المنهج الوصفي التحليلي، المنهج الوصفي الارتباطي.

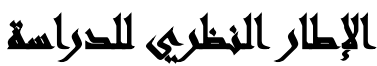

ومن النظريات التي ساهمت في تفسير عملية المشكلات الاجتماعية والنفسية ما يلي:

ا - النظرية البنائية الوظيفية:

أ- الوظيفية الكلاسيكية: حاولت الوظيفية الكلاسيكية تفسير المشكلات الاجتماعية من خلال محاولة فهم المجتمع في ضوء الظروف التي يمر بها، أب من خلال محاولة فهم العلاقات

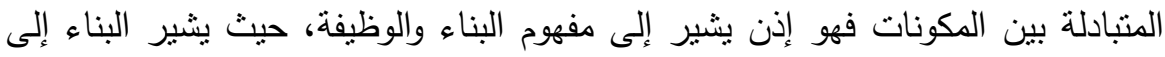
العلاقات المستمرة والثابتة بين الوحدات الاجتماعية ويكثف عن الجوانب الهيكلية الثابتة

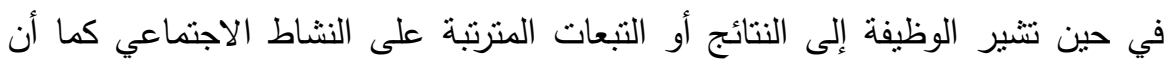

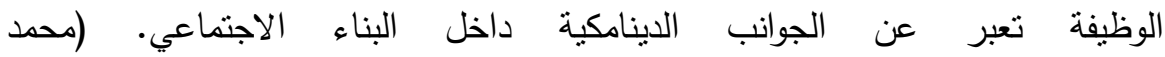

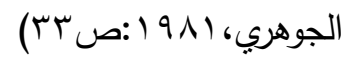

تفسير المشكلات الاجتماعية من وجهة النظر (Herbert spencer) ويحاول هربرت سبنسر الكلاسيكية من خلال "تقديم مقاربة عضوية بين المجتمع والمادة الحية ، حيث يتغير المجتمع في ضوء نفس القوانين التي يتحول بها عالم المادة إذ تتحول من وضعية اللاتجانس

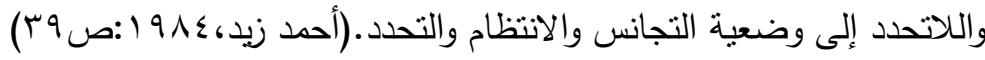




\section{النظريــات المفســـرة للتكيف:}

1-النظرية الإنسانية: تؤكد للنظرية الإنسانية من خلال روجرز أن الأفراد الذين يعانون من

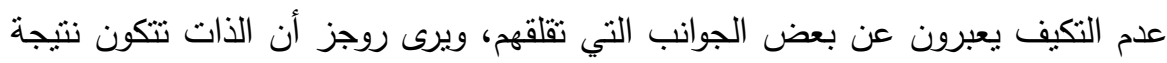
التفاعل مع البيئة وقد تمتص قيم الآخرين وتسعى إلى التكيف والاتزان نتيجة للنضج والتعلم وهي محور كل الخبرات السابقة، والفرد يمر في حياته بخبرات عديدة بوئثر فيها ويتأثر بها ويحول هذه الخبرات إلى رموز يدركها ويقيمها في ضوه مفهوم الذات والمعايير

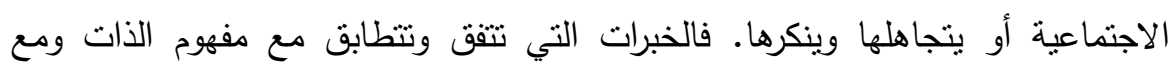

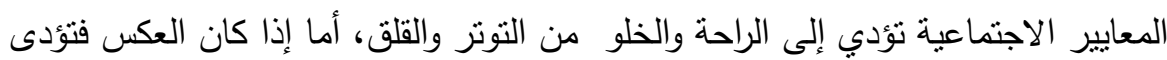

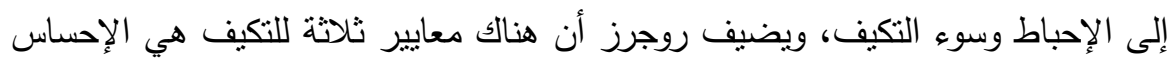

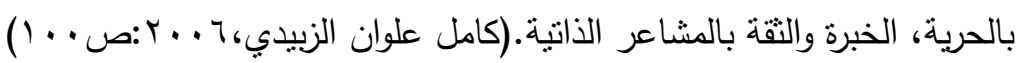

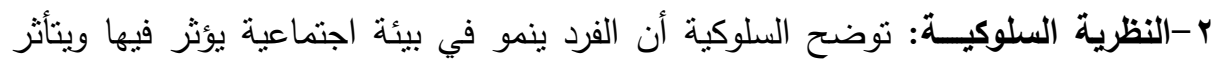
بها، ويكتسب منها أنماط الحياة والمعايير الاجتماعية والتي تكون مجموعة من المحددات

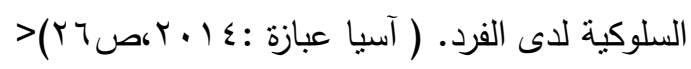
وأنماط التكيف وسوء التكيف تعد متعلمة أو مكتسبة وذللك من خلال الخبرات التي يتعرض لها الفرد والتكيف يشمل على خبرات تتشير إلى كيفية الاستجابة لتحديات الحياة تقابل

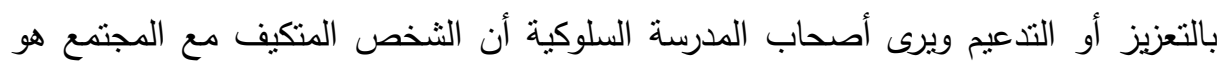
الثخص الذي استطاع أن يكون عادات سوية نتجت من خلال ارتباطات بمتغيرات حسية

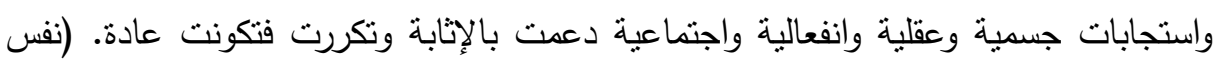

\section{الإجبراعايت المنهمجية}

\section{1- 1 - منهج الدراسة:}

- المنهج الوصفي: اعتمد الباحثون على المنهج الوصفي التحليلي الذي يعمل على وصف

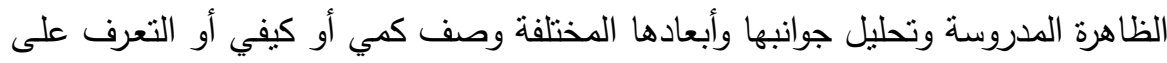

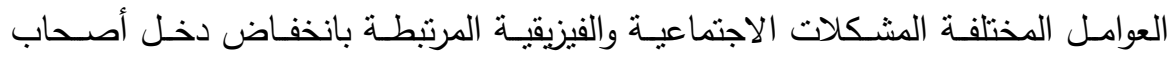


المعاشات وسبل التكيف الاجتماعي والنفسي والبيئي معها المسؤولية وكثف الحقائق التي تتعلق بها. - منهج المسح الاجتماعي: يعد هذا المنهج من أكثر المناهج العلمية شيوعاً واستخداماً في البحوث الاجتماعية وقد تم استخدام هذا المنهج حيث أنه يسمح بأخذ أعداد كبيرة وذلك الكي على عينة الدراسة باستخدام أداة الاسنتيان في جمع المعلومات المات الميدانية. r - نوع الاراسة: تعد هذه الدراسة من الدراسات الوصفية التي تسعى إلى وصف مجتمع الدراسة واستخدام التحليل بنوعيه (الكمي - الكيفي) ، حيث إن الدراسات الوصفية توفر

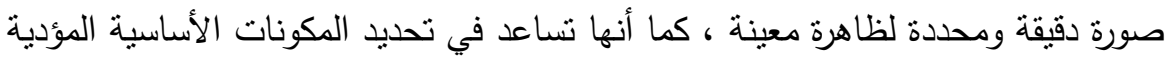
إلى وصف وتتخيص وتحليل الظواهر في المجتمع للكثف عن الشكلات الاجنماعية والفيزيقية المرنبطة بانخفاض دخل أصحاب المعاشات وسبل التكيف الاجتماعي والنفسي

أما مصدر البيانات فقد نم الحصول عليها من مصدرين هما: أ - المصادر الثانوية: حيث اتجهت الباحثة في معالجة الإطار النظري للاراسة إلى مصادر

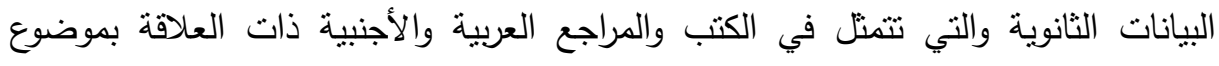
الدراسة، والدوريات والمقالات والثقارير ، والأبحاث والدراسات السابقة التي تتاولت موضوع لهابه الدارسة، والبحث والمطالعة في مواقع الإنترنت المختلفة. ب - المصادر الأولية: وتتمثل في جمع البيانات الأولية ميدانياً.

1-استمارة الاستييان (Questionnaire): من إعداد الباحثون: هي عبارة عن نموذج

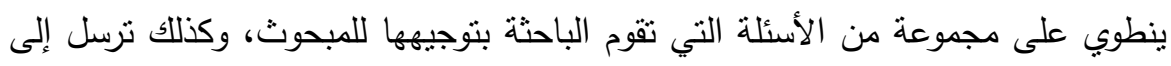
المبحوث عن طريق البريد ، ومن ثم يقوم المبحوث بتسجيل إجاباته بنفسه. (إسماعيل علي لئي

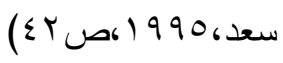
مرحلة تصميم الاستمارة وصياغة الأسئلة: مرحلة تحديد الغرض من البيانات: 
مرحلة ترجمة المفاهيم النظرية للبحث إلى صيخ إجرائية: مرحلة الصياغة المبئية للاستنيان ليكون قابلاً للتجريب:

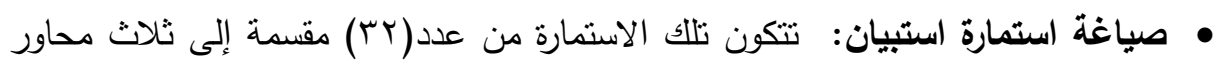

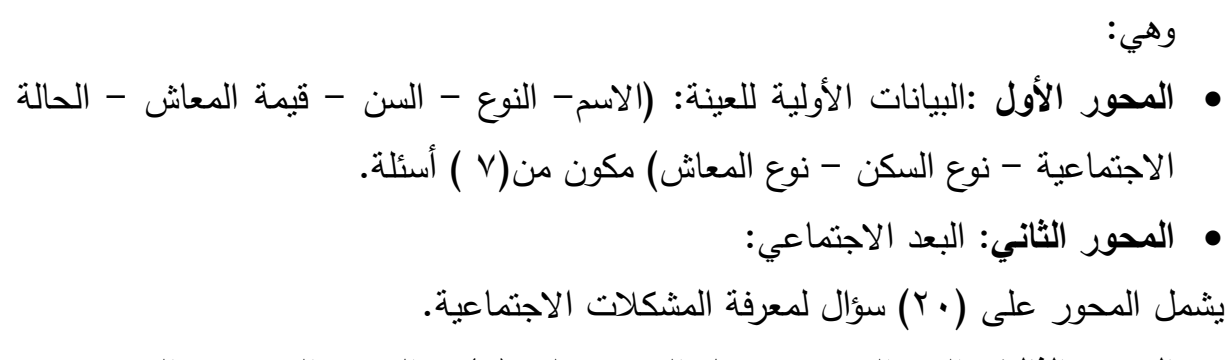
• المحور الثالث: البعد الفيزيقي: يشمل المحور على (0) سؤال عن المشكلات الفيزيقي. r-مقياس التكيف(الاجتماعي والنفسي والبيئي): (إعداد الباحثون) ا ـ إعداد جدول مواصفات المقياس: جدول رقم (1): أبعاد مقياس التكيف (الاجتماعي -النفسي- البيئي) وأرقام المفردات داخل كل

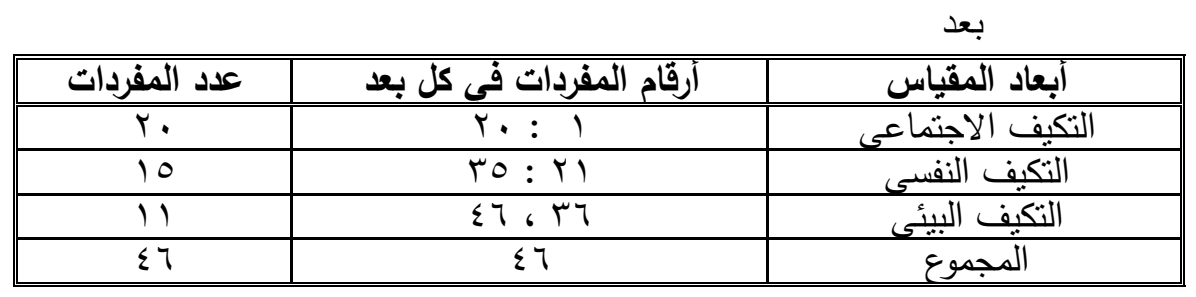

المقياس كله يعطى للإجابة الأولى ( r درجات )، والإجابة الثانية ( درجتان ) والإجابة

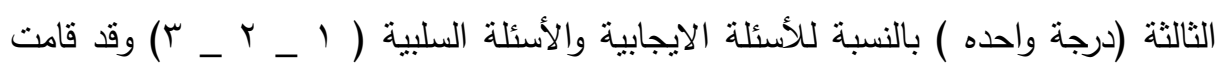
الباحثة بحساب المتوسط المرجح لاستجابات السادة المحكمين على الأسئلة الواردة في شكل الإنه تدرج ثلاثي، حيث يعد من أفضل أساليب قياس الاتجاهات. ويستخدم المتوسط المرجح إذابات الذادئ

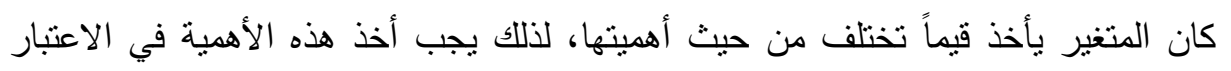

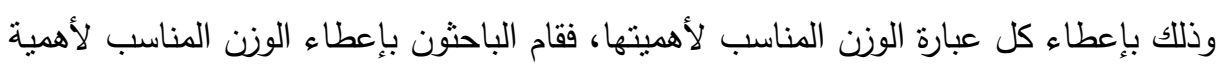
كل عبارة من عبارات المقياس. 


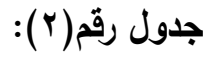

\begin{tabular}{|c|c|c|c|c|}
\hline \multicolumn{2}{|c|}{ العبارات السلبيةة } & \multicolumn{3}{|c|}{ العبارات الإيجابية } \\
\hline الوزن I & تتطبق & T & الوزن & تتطبق \\
\hline كزن r r & أحيانا & r & الوزن & أحيانا \\
\hline الوزن r & لا تتطبق & 1 & الوزن & لا تتطبق \\
\hline
\end{tabular}

الخصائص السيكومتريه للمقياس: للتأكد من صدق وثبات المقياس نم تطبيق المقياس في لإن

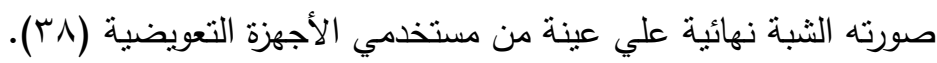
الصدق: اعتمد الباحث علي استخدام الطرق التالية للتأكد من: صدق البناء: نم الاطلاع علي المقاييس السابقة والأطر النظرية ذات الاهتمام بالمرونة النفسية، ثم الدراسات السابقة ألخاصة بالموضوع للتمكن من إعداد عبارات المقياس.

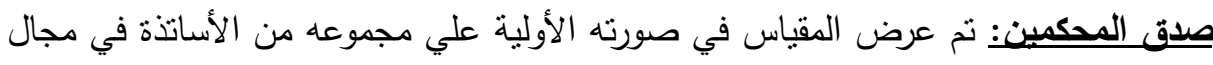

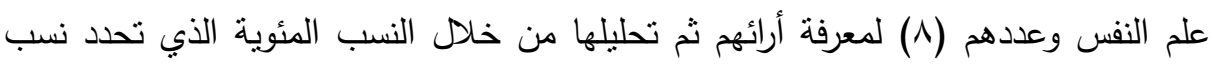
قبول كل عبارة تبعا لأراء السادة المحكمين. 1. صدق الاتساق الداخلي للمقياس: تم التحقق من الاتساق الداخلي لمقياس التكيف لدى أصحاب المعاشات منخفضي الاخل خلال التطبيق الذي نم للمقياس على العنى العينة الاسنطلاعية التي قوامها (•r) فرداً كما يلي: حساب معاملات الارتباط بين عبارات المقياس والدرجة الكلية للمقياس: 
جدول رقم (ץ): معاملات الارتباط بين عبارات المقياس والدرجة الكلية للبعد وعبارات المقياس والدرجة الكلية للمقياس

\begin{tabular}{|c|c|c|c|c|c|c|c|c|}
\hline 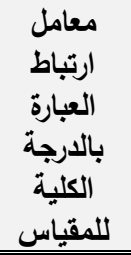 & 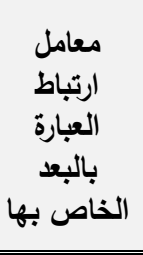 & العبارة & 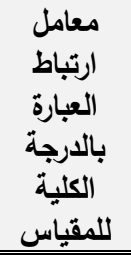 & الخاص العبارة & العبارة & 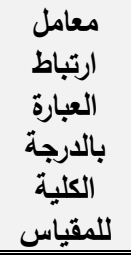 & الخاص البالبعل بارة & العبارة \\
\hline$* *, \wedge \uparrow$. & $* *,, \mathrm{r}$, & זr & $* * \cdot V T r$ & $* *, Y Y I$ & IV & $* *, V \cdot q$ & $* *,, \leq 0 \leq$ & 1 \\
\hline$* *, 07 r$ & $* *, 70$ & r乏 & $* *, \vee Y \wedge$ & $* *, 7 \wedge 1$ & 11 & $* *, V Y T$ & $*, 19$. & $r$ \\
\hline$* \cdot \Gamma \wedge \wedge$ & $* *, V \leq \nearrow$ & ro & $* *, \nearrow, \Lambda$ & $* *, \leqslant \vee q$ & 19 & $* *, \vee \backslash \mathrm{V}$ & $* *, r \leq r$ & $r$ \\
\hline$* *, 709$ & $* .079$ & ד & $* *, \wedge \wedge r$ & $* *, \vee \vee 91$ & $r$. & $* *, T \vee$. & $* *, 0 \leq V$ & $\varepsilon$ \\
\hline$* *, \vee \vee 71$ & $* *, 709$ & $r v$ & $* *, \vee \vee \backslash 1$ & $* *, 7.9$ & rI & $* *, \tau ו r$ & $* *, 70 \leq$ & 0 \\
\hline$* *, 791$ & $* *, 0 \leq 0$ & rᄉ & $* *, 107$ & $* *, 009$ & rr & $* *, \vee \vee \neg$. & $* *,, \vee \Gamma$, & 7 \\
\hline$* *, \vee \vee q$. & $* *, T V Y$ & rq & $* *, \vee \wedge \Lambda$ & $* *, \vee \vee 70$ & rT & $* * .07 r$ & $* *, \ldots 0$. & V \\
\hline$* *, 791$ & $* *$, , $\vee 99$ & $\varepsilon$. & $* *, 70 \mathrm{~V}$ & $* *, 7 \cdot \Lambda$ & $r \varepsilon$ & $*$, * r & $* *,, \leq \leq 7$ & $\wedge$ \\
\hline$* *, \wedge \vee r$ & $* *, \vee \vee \vee I$ & $\leqslant 1$ & $* *, V \leq r$ & $* *, 701$ & ro & **., $7 \mu \leq$ & $*, Y 79$ & 9 \\
\hline$* *, \vee \wedge \wedge 1$ & $* *, v, q$ & $\varepsilon r$ & $* *, 7 Y q$ & $* * .099$ & $r T$ & $* *, V \cdot 1$ & $* *, \leqslant 09$ & 1. \\
\hline$* *, 74 \mathrm{~V}$ & $* *, 0 \wedge 9$ & $\varepsilon r$ & $* *, \Lambda \cdot V$ & $* *, 711$ & $r V$ & $* *, 7,1$ & $* *, 7 \leq 0$ & 11 \\
\hline **, Тル人 & $* *, 070$ & $\varepsilon \varepsilon$ & $* *, 70$. & $* *, T \leq \Gamma$ & $r \wedge$ & $* *, \Upsilon 7$. & $* *, 77 r$ & Ir \\
\hline$* *, \mathrm{~V} \circ \mathrm{V}$ & $* *, \vee \cdot \wedge$ & $\leq 0$ & $* *, 0.9$ & $* *, v \cdot 1$ & rq & $* *, V \cdot r$ & $* *, 70$ & 15 \\
\hline$* *, V \leq r$ & $* *, 7 \wedge 1$ & $\leqslant 7$ & $* *, 009$ & $* *, \wedge \cdot 1$ & $r \cdot$ & $* *, T \vee \cdot$ & $*, \Pi \wedge$ & $1 \leqslant$ \\
\hline$* *, 779$ & $* *, \vee \vee 99$ & & $* *, T T V$ & $* *$, TV. & rI & $* *, T \vee$. & $* *, \Sigma)$. & 10 \\
\hline$* *, \vee \vee 71$ & $* *, \vee \vee 0$. & & $* *, \vee \wedge \vee$ & $* *, \wedge \vee$. & rt & $* *, \vee \vee \uparrow$. & $* *, 7 \wedge \uparrow$ & 17 \\
\hline
\end{tabular}

*** دالة عند مستوى (0., *.

"دالة عند مستوى (1, (•, (•)

يتضح من الجدول السابق أن معاملات الارتباط بين العبارات والدرجة الكلية للبعد التي

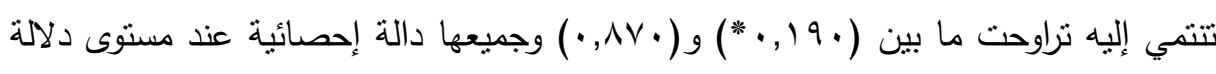

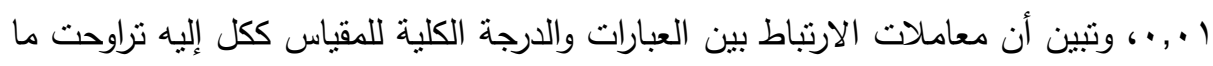

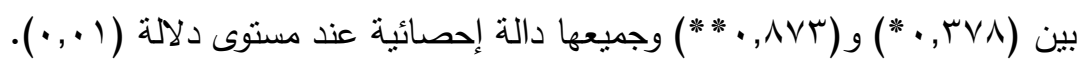


ثبات المقياس Test reliability:

1. طريقة إعادة التطبيق:تم حساب معامل الثبات لأبعاد المقياس المختلفة، والمقياس الكلى

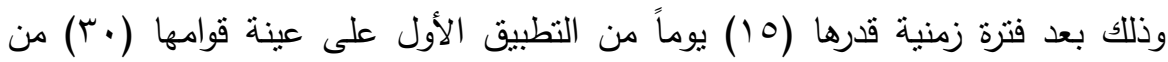
أصحاب المعاشات منخفضي الدخل. جدول رقم ( )): معاملات الثبات لجميع أبعاد مقياس التكيف (الاجتماعي والنفسي والبيئي)

\begin{tabular}{|c|c|c|}
\hline مستوى الدلالة (1, +, & معاملات الثبات & آبعاد مقياس التكيف \\
\hline دالة & $\cdot, \wedge \wedge \mathrm{V}$ & التكيف الاجتماعي \\
\hline دالة & $\cdot, \Lambda Y \cdot$ & التكيف النفسي \\
\hline 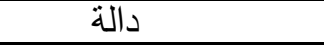 & $\cdot, \Lambda \cdot V$ & التكيف البيئي \\
\hline دالة & $\cdot, \Lambda \wedge \Gamma$ & المقياس الكلح \\
\hline
\end{tabular}

$$
\text { ومن خلال الجدول السابق يتضح ما يلي: }
$$

• تم حساب معامل الارتباط بين التطبيقين الأول والثاني وذلك بالنسبة لمقياس التكيف الاجتماعي ككل، وكان قدرة (A^V, · ) ينسم بدرجه عالية من الثبات. • تم حساب معامل الارتباط بين التطبيقين الأول والثاني وذلك بالنسبة لبعد التكيف التهن النفسي

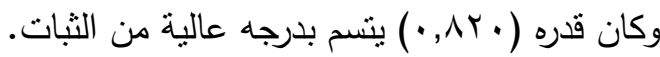
• تم حساب معامل الارتباط بين النطبيقين الأول والثاني وذللك بالنسبة لبعد التكيف البيئي

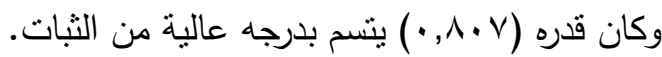

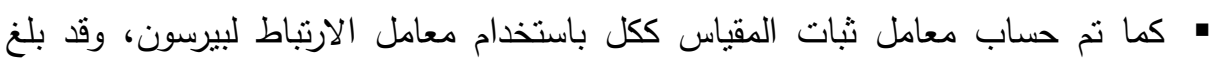

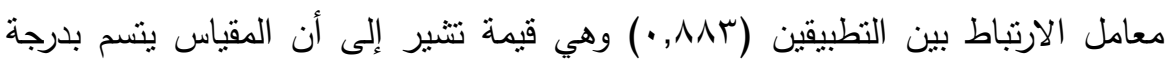
عالية من الثبات وبهذا يكون قد نم التحقق من وجود علاقة ذات دلاله إحصائية بين التطبيقين ( الأول والثاني ) للمقياس المستخدم وهذا يدل على ثبات المقياس.

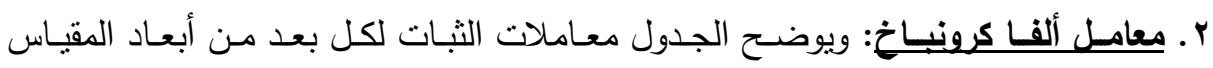

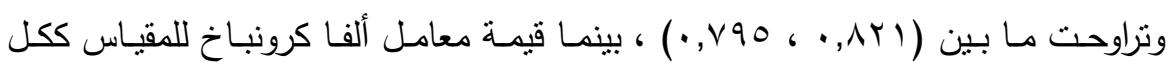


جدول رقم (•): قيم معامل الثبات لكل بعد من أبعاد مقياس التكيف وللمقياس ككل التعاد

\begin{tabular}{|c|c|c|}
\hline معامل آلفا كرونباخ & عدد العبارات & الأبعاد \\
\hline$\cdot, \wedge Y I$ & r. & التكيف الاجتماعي \\
\hline$\cdot, 1 \vee 90$ & 10 & التكيف النفسي \\
\hline$\cdot, \vee \vee 4$. & 11 & التكيف البيئي \\
\hline$\cdot, \wedge \wedge 0$ & $\sum 7$ & المقياس الكلي \\
\hline
\end{tabular}

وتدل هذه القيم على أن المقياس يتمتع بدرجة مناسبة من الثبات لقياس التكيف لدى

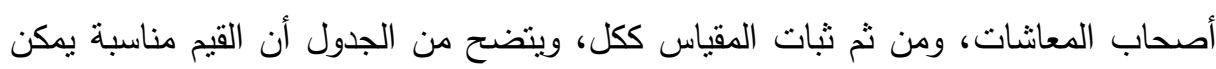
الوثنوق بها وتدل على صلاحية المقياس للتطبيق. r-المقابلة: المقابلة هي التفاعل اللغوي بين الباحثون والمبحوث بالإضافة إلى المرونة في

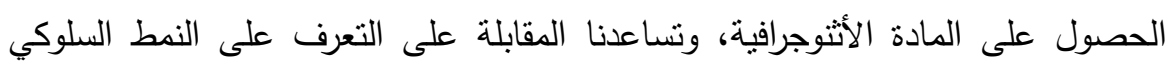

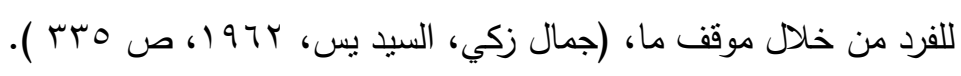

ع- الملاحظة: تعد الملاحظة والملاحظة بالمشاركة أداتان هامتان في علم الاجتماع والنفس

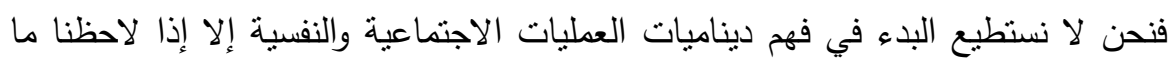

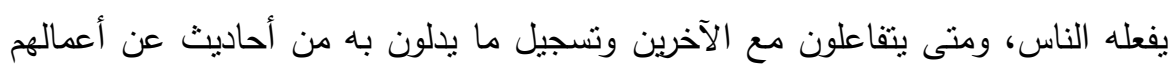

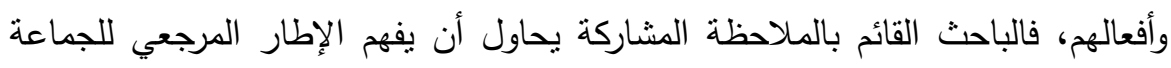

$$
\text { التي يدرسها.(عدلي السمري، ب ( • ب: r • (1). }
$$

\section{هجالإه الصواسمة}

المجال الجغرافي: طبق المقياس والاستبيان على.التأمينات الاجتماعية بمنطقة الزيتون.

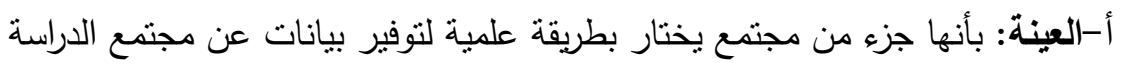
العينة مقسمة إلي: باني جاء

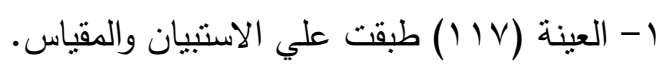

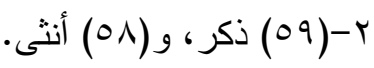




\section{نتمأيج التواسمة}

النتائج المتعلقة بالفرض الأول وتفسيره:

نص الفرض الأول: توجد علاقة ذات دلالة إحصائية بين المشكلات الاجتماعية وقيمة المعاش لاى أصحاب المعاشات المنخفضة".

وللتحقق من هذا الفرض قامـت الباحثـة بإنبـاع الخطوات التاليـة: حسـاب معامل الارتبـاط (بيرسون) للتعرف على مدى قوة العلاقة بين المشكلات الاجتماعية وانخفاض دخل أصحاب

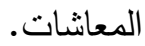
جدول رقم (†): العلاقة بين المشكلات الاجتماعية وقيمة المعاش

\begin{tabular}{|c|c|}
\hline WV = ن & المشكلات الاجتماعية \\
\hline 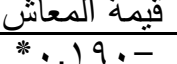 & 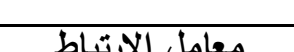 \\
\hline$\cdot, \cdot \varepsilon$. & الدالة \\
\hline
\end{tabular}

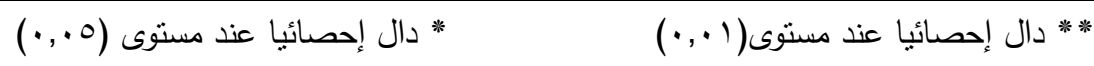

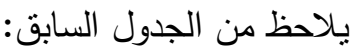

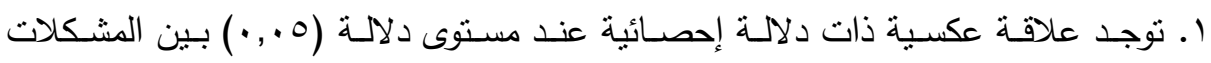

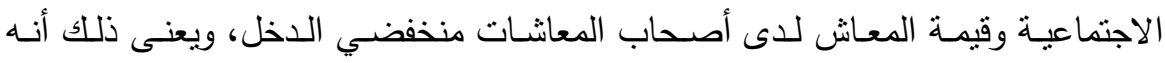
ويعنى ذلك أنه انخفاض مستوى الدخل لدى أصحاب المعاشات له علاقة بزيادة المشكلات الاجتماعية. وقد تبين مما سبق وجود علاقة عكسية ذات دلالة إحصائية ومن الدراسات التي اتفقت مع الدراسة الحالية في بين المشكلات الاجتماعية وقيمة المعاش لدى أصحاب المعاثات دات داته منخفضي الاخل: - دراسة (خليل درويش: r . . r): حيث بينت أن عزلتهم عن الآخرين المشكلات النفسية والاجتماعية وبخاصة شعور المسنين بالحزن والكآبة الناجم. لمان.

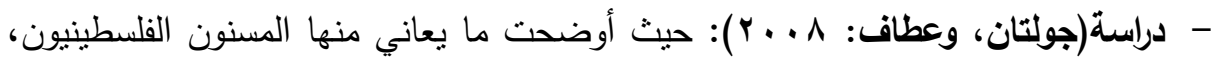
المشاكل الاجتماعية الاقتصادية. 


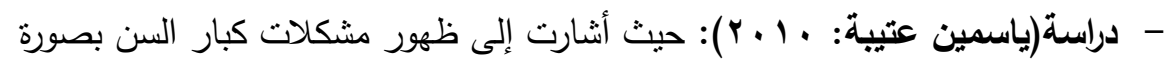
واضحة وأن اختلفت في درجة أهمية كل منها،حيث كانت أول هذه المشكلات من حيث الثيث الأهمية المشكلات الاقتصادية.

وقد تبين مما سبق وجود علاقة عكسية ذات دلالة إحصائية ومن الدراسات التي أتخلفت

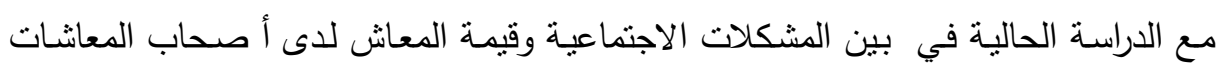
منخفضي الاخل: - - دراسة (عماد محمد:ه . . ب): حيث أنشارت إلى وجود علاقة طردية معنوية بين كل من (الدخل الثهري) وتحسين نوعية حياة المسنين. النتائج المتعلقة بالفرض الثاني وتفسيره: • ــص الفرض الثـاني: لا توجد فروق ذات دلاتلـة إحصـائية في المشكلات الاجتماعيـة

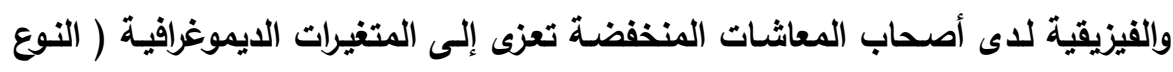

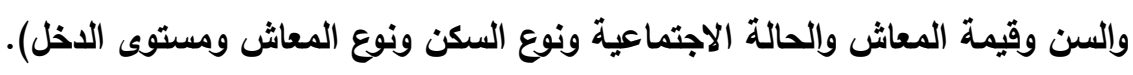
وللتحقق من هذا الفرض قام الباحث بإتباع الخطوات التالية:

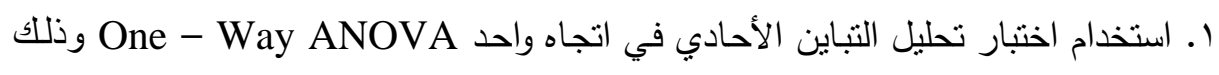
للتعرف على أنه هل هناك تأثير لكلا من (السن وقيمة المعاش والحالة الاجتماعية ونوع الجاه وادئ المعاش) على استجابات أصحاب المعاشات حول المشكلات الاجتماعية والفيزيقية.

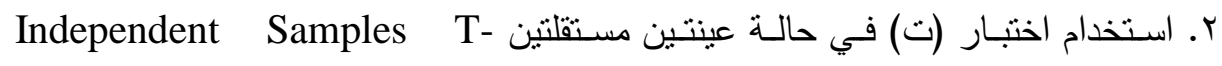
Test استجابات أصحاب المعاثنات حول المشكلات الاجتماعية والفيزيقية.

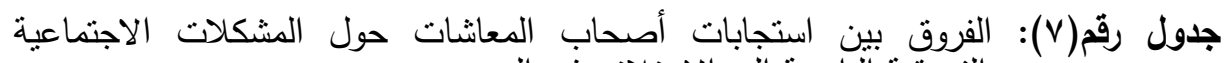

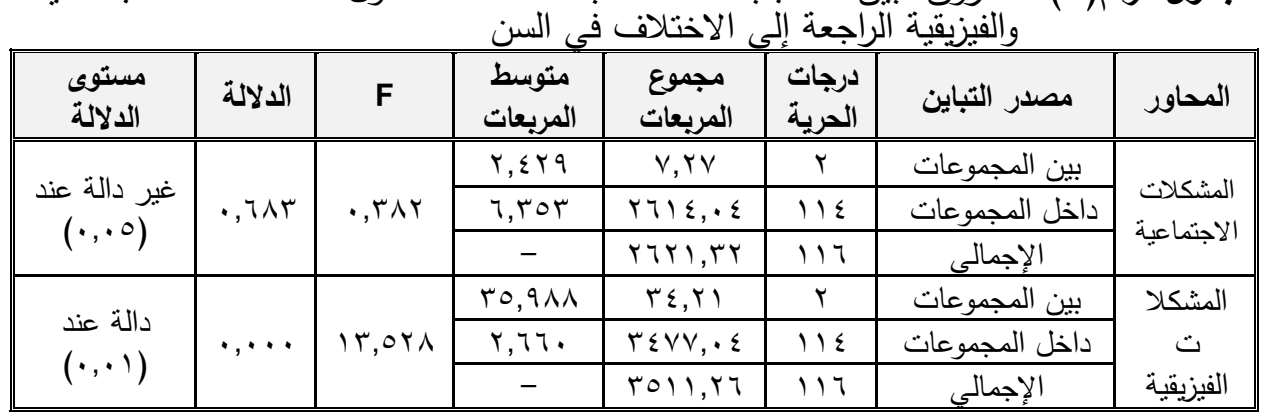




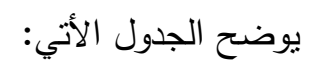

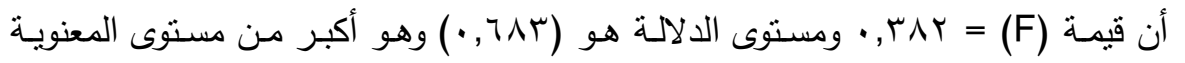

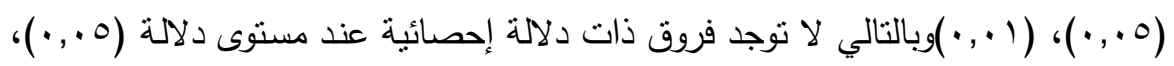

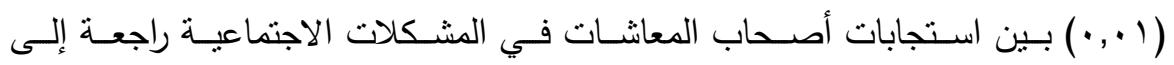
الاختلاف في " السن "، وبالتالي لا يوجد تأثثر معنوي لاختلاف السن على استجابات أصحاب المعانشات حول المشكلات الاجنماعية.

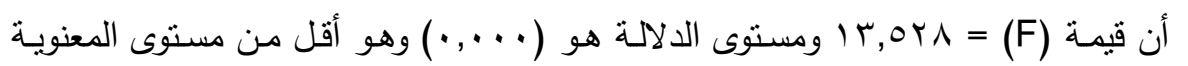

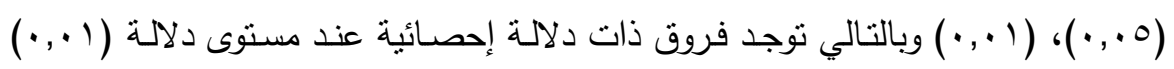

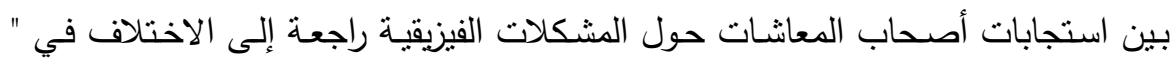
السن "، وبالتالي يوجد تأثنر معنوي لاختلاف السن على استجابات أصحاب المعانشات حول المشكلات الفيزيقية. وقد تبين ممـا سبق وجود فروق ذات دلالـة إحصـائية ومـن الدراسـات التـي اتفقت مـع

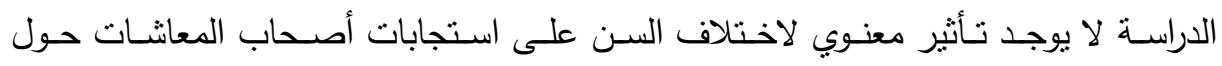
المشكلات الاجتماعية.

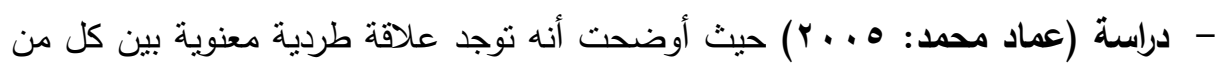

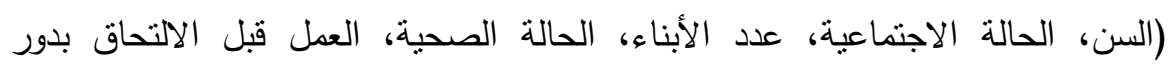
الرعاية، الدخل الثهري) وتحسين نوعية حياة المسنين. - اتفقت مع النظرية البنائية الوظيفية الزيادة في درجة التباين نؤدي إلى زياد التيهاة التتوع الثقافي

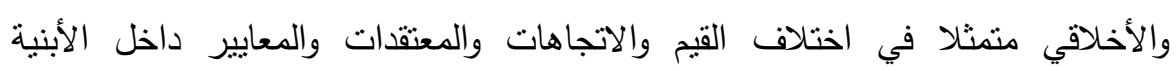
الاجتماعية بفئاتها ومستوياتها. (Rocher, (1911). (191).

النتائج المتعلقة بالتساؤل الرابع وتقسيره :

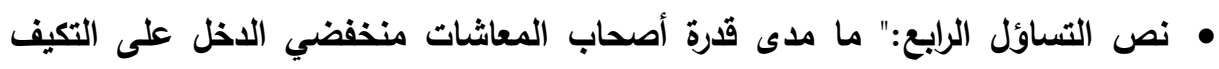

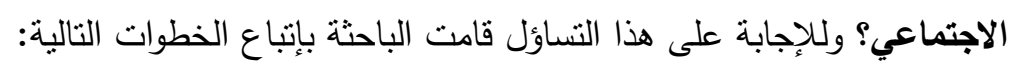

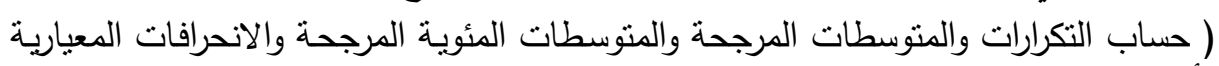
لأسئلة محور التكيف الاجتماعي).

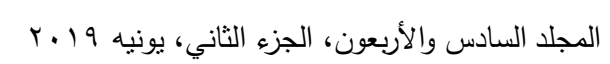


آيه عبد المرضي وآخرون

جدول رقم(^): المتوسطات المرجحة والمتوسطات المئويـة المرجحة والانحرافات المعياريـة

\begin{tabular}{|c|c|c|c|c|c|c|c|c|c|c|}
\hline \multirow{2}{*}{ بتربت } & \multirow{2}{*}{ المئويط } & \multirow{2}{*}{ الانحراف } & \multirow{2}{*}{ المرجح } & \multirow{2}{*}{ الأوزلان } & \multicolumn{3}{|c|}{ مستويات التدرج } & & \multirow[b]{2}{*}{ المؤشرات } & \multirow[b]{2}{*}{ e } \\
\hline & & & & & لا تنطبق & أحياناً & تنطبق & & & \\
\hline \multirow{2}{*}{ r } & $\Lambda \varepsilon, .0$ & \multirow{2}{*}{$\cdot, 0 . r$} & \multirow{2}{*}{ r,or } & \multirow{2}{*}{ r9o } & . & 07 & 71 & التكرار & \multirow{2}{*}{ وأسرتاقك مستمرة بأقاربك } & \multirow{2}{*}{1} \\
\hline & $\%$ & & & & . & $\% \leq \vee, q$ & $\% \circ r, 1$ & $\%$ & & \\
\hline \multirow[b]{2}{*}{1} & \multirow{2}{*}{$\begin{array}{l}\wedge \uparrow, \wedge 9 \\
\%\end{array}$} & \multirow[b]{2}{*}{$\cdot,\{91$} & \multirow[b]{2}{*}{$r, r)$} & \multirow[b]{2}{*}{$r .0$} & . & $\leq 7$ & vi & التكرار & \multirow{2}{*}{ زأحافظ على أصدقائي } & \multirow[b]{2}{*}{ r } \\
\hline & & & & & - & $\%$ \%, r & $\% \curlyvee \cdot, \vee$ & $\%$ & & \\
\hline \multirow[b]{2}{*}{9} & \multirow[b]{2}{*}{$\begin{array}{c}71,0 \leq \\
\%\end{array}$} & \multirow[b]{2}{*}{ גו } & \multirow[b]{2}{*}{1,10} & \multirow[b]{2}{*}{ Y14 } & $r \varepsilon$ & $7 V$ & 17 & التكرار & \multirow{2}{*}{ أجدأ ألشاركة في } & \multirow[b]{2}{*}{$r$} \\
\hline & & & & & $\% \curlyvee q, 1$ & $\% \circ v, r$ & $\%$ \%r,v & $\%$ & & \\
\hline \multirow{2}{*}{11} & \multirow{2}{*}{$\begin{array}{c}\circ \wedge, 9 \vee \\
\%\end{array}$} & \multirow{2}{*}{$\cdot, T \vee \leq$} & \multirow{2}{*}{$1, v V$} & \multirow{2}{*}{ (YT) } & 17 & 01 & $\varepsilon r$ & التكرار & \multirow{2}{*}{ أعانى من } & \multirow{2}{*}{$\varepsilon$} \\
\hline & & & & & $\% \backslash r, v$ & $\% \leq १, 7$ & $\%$ \%ч,^ & $\%$ & & \\
\hline & & & & & 17 & TV & $r \varepsilon$ & التكرار & خروجي على & \\
\hline 1. & $\begin{array}{c}71,0 \leq \\
\%\end{array}$ & 政, & 1,10 & ror & $\% / r, v$ & $\% \circ v, r$ & \%rq, 1 & $\%$ & الصغان الجمات المقدني غير & 0 \\
\hline & & & & & $\varepsilon$ & or & 7. & التكرار & يصعب علي & \\
\hline$\varepsilon$ & $\begin{array}{c}\wedge r, T r \\
\%\end{array}$ &., 074 & $r, \varepsilon \wedge$ & rq. & $\% \curlyvee, \varepsilon$ & $\% \varepsilon 0, r$ & $\% 01, r$ & $\%$ & الذأشخر بعض لاصل أنعامل & 1 \\
\hline & & & & & . & 07 & 71 & التكرار & يزعجني & \\
\hline iv & $\begin{array}{c}\sum q, r q \\
\%\end{array}$ & , O. & $1, \varepsilon \wedge$ & r9o & . & $\% \varepsilon v, q$ & \%०r, 1 & $\%$ & المحيطة بلمبرات & v \\
\hline & r9.7. & & & & . & rr & 90 & التكرار & يضايقني & \\
\hline$r$. & $\%$ & • r rqr & 1,19 & rrq & . & $\% \backslash \wedge, \wedge$ & $\% \wedge 1, r$ & $\%$ & انصراف أولادي & $\wedge$ \\
\hline
\end{tabular}


مجلة العلوم البيئية

معهد الدراسات والبحوث البيئية - جامعة عين شمس لئس

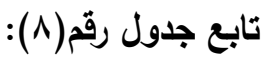

\begin{tabular}{|c|c|c|c|c|c|c|c|c|c|c|}
\hline \multirow{2}{*}{ ب بترتي } & \multirow{2}{*}{ المئويط } & \multirow{2}{*}{ الانعراف } & \multirow{2}{*}{ المرجح } & \multirow{2}{*}{ الأوزان } & \multicolumn{3}{|c|}{ مستويات التدرج } & & \multirow[b]{2}{*}{ المؤشرات } & \multirow[b]{2}{*}{ p } \\
\hline & & & & & لا تنطبق & أحياناً & تنطبق & & & \\
\hline \multirow[b]{2}{*}{$r$} & \multirow[b]{2}{*}{$\begin{array}{c}\wedge r,\{\wedge \\
\%\end{array}$} & \multirow[b]{2}{*}{$\cdot, V 41$} & \multirow[b]{2}{*}{ r,O. } & \multirow[b]{2}{*}{ ivo } & $\mathrm{VA}$ & $r$. & 19 & التكرار & \multirow{2}{*}{ أجدأ ألتواصل } & \multirow[b]{2}{*}{9} \\
\hline & & & & & $\% \pi 4, \vee$ & $\% \backslash \vee, 1$ & $\% 17, r$ & $\%$ & & \\
\hline \multirow{2}{*}{$1 \pi$} & \multirow{2}{*}{$\begin{array}{c}0 \wedge, \varepsilon \cdot \\
\%\end{array}$} & \multirow[b]{2}{*}{$\cdot, 710$} & \multirow{2}{*}{1, vo } & \multirow{2}{*}{ זדו } & 11 & 77 & $\varepsilon$. & التكرار & \multirow{2}{*}{ الانسحاب دائماً } & \multirow[b]{2}{*}{1.} \\
\hline & & & & & $\% १, \varepsilon$ & $\% 07, \varepsilon$ & $\% r \varepsilon, r$ & $\%$ & & \\
\hline \multirow{2}{*}{0} & & \multirow{2}{*}{$\cdot, 011$} & \multirow{2}{*}{$\Upsilon, \Sigma \wedge$} & \multirow{2}{*}{ IVA } & 71 & 01 & 。 & التكرار & \multirow{2}{*}{ لا يوجد لدى أصدقاء } & \multirow{2}{*}{11} \\
\hline & $\%$ & & & & $\% \circ r, 1$ & $\% \leqslant r, r$ & $\% 乞, r$ & $\%$ & & \\
\hline \multirow[b]{2}{*}{10} & \multirow[b]{2}{*}{$\begin{array}{c}\text { or, } 99 \\
\%\end{array}$} & \multirow[b]{2}{*}{$\cdot, V T V$} & \multirow[b]{2}{*}{1,09} & \multirow[b]{2}{*}{ rAT } & r. & rq & 71 & التكرار & \multirow{2}{*}{ 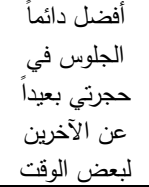 } & \multirow[b]{2}{*}{ ir } \\
\hline & & & & & $\% \backslash \vee, 1$ & $\% r \varepsilon, \wedge$ & $\% \circ \wedge, 1$ & $\%$ & & \\
\hline \multirow[b]{2}{*}{1} & & & & & rv & $0 \leqslant$ & ru & التكرار & أنسحب من & \\
\hline & $\begin{array}{c}79, \wedge . \\
\%\end{array}$ & $\cdot, \mathrm{VTr}$ & $r, .9$ & TrT & $\% r 1,7$ & $\% \leqslant 7, r$ & $\% r r, r$ & $\%$ & 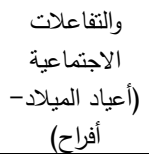 & $\pi$ \\
\hline & & & & & rr & $\varepsilon r$ & 01 & التكرار & فيكف أنشعر بنقي & \\
\hline ir & $\begin{array}{c}01,79 \\
\%\end{array}$ & 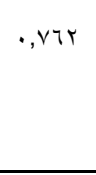 & 1,14 & Trז & $\% \backslash 9, \vee$ & $\%$ \% , А & $\% \varepsilon r, \uparrow$ & $\%$ & 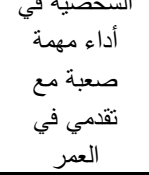 & $1 \varepsilon$ \\
\hline & & & & & 1 & AT & rT & التكرار & ينخفض & \\
\hline $1 \varepsilon$ & $\begin{array}{c}0 v, 00 \\
\%\end{array}$ & $\cdot, \leq T V$ & $1, \mathrm{~V} r$ & rצ4 & $\% \cdot, 9$ & $\% \vee \cdot, q$ & $\% \curlyvee \wedge, r$ & $\%$ & 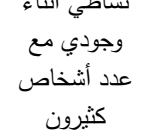 & 10 \\
\hline
\end{tabular}

المجلد السادس والأربعون، الجزء الثاني، يونيه 9 1 ب 
آيه عبد المرضي وآخرون

تابع جدول رقم(^):

\begin{tabular}{|c|c|c|c|c|c|c|c|c|c|c|}
\hline \multirow{3}{*}{ ب بتربي } & \multirow{3}{*}{ المئوسط } & \multirow{3}{*}{ الانحراف } & \multirow{3}{*}{ المرجح } & \multirow{3}{*}{ الأوزان } & \multicolumn{3}{|c|}{ مستويات التدرج } & & \multirow{3}{*}{ المؤشرات } & \multirow{3}{*}{ p } \\
\hline & & & & & لا تنطبق & أحياناً & تنطبق & & & \\
\hline & & & & & $\% \cdot, q$ & $\% v_{\cdot, q}$ & $\% \curlyvee \wedge, r$ & $\%$ & & \\
\hline \multirow[b]{2}{*}{17} & \multirow[b]{2}{*}{$\begin{array}{c}01, Y \wedge \\
\%\end{array}$} & \multirow[b]{2}{*}{$\cdot, \wedge \cdot \varepsilon$} & \multirow[b]{2}{*}{$1,0 \leqslant$} & \multirow[b]{2}{*}{ rAM } & rT & IV & VV & التكرار & \multirow{2}{*}{ 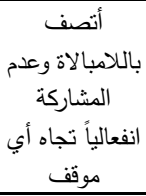 } & \multirow[b]{2}{*}{17} \\
\hline & & & & & $\% \backslash 9, \vee$ & $\% \backslash \leqslant, 0$ & $\%$ \% & $\%$ & & \\
\hline \multirow[b]{2}{*}{19} & \multirow{2}{*}{$\begin{array}{c}\varepsilon 0, r . \\
\%\end{array}$} & \multirow[b]{2}{*}{ •, $\{\wedge r$} & \multirow[b]{2}{*}{$1, \pi 4$} & \multirow[b]{2}{*}{$r .9$} & . & $\varepsilon r$ & vo & التكرار & \multirow{2}{*}{ تجاهل أسرني أفراد } & \multirow[b]{2}{*}{ IV } \\
\hline & & & & & . & $\%$ ro, $q$ & $\%\ulcorner\varepsilon, 1$ & $\%$ & & \\
\hline \multirow[b]{2}{*}{ v } & \multirow{2}{*}{$\begin{array}{c}T V, Y \leq \\
\%\end{array}$} & \multirow[b]{2}{*}{$\cdot, \vee>9$} & \multirow[b]{2}{*}{$r, \cdot r$} & \multirow[b]{2}{*}{ rrt } & 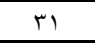 & ov & rq & التكرار & \multirow{2}{*}{ إحالتي على التقاعد } & \multirow[b]{2}{*}{11} \\
\hline & & & & & \%४ч,० & $\% \varepsilon \wedge, \vee$ & $\% r \varepsilon, \wedge$ & $\%$ & & \\
\hline \multirow[b]{2}{*}{$\wedge$} & \multirow{2}{*}{$\begin{array}{c}10, r \varepsilon \\
\%\end{array}$} & \multirow[b]{2}{*}{$\cdot, \mathrm{YAl}$} & \multirow[b]{2}{*}{1,97} & \multirow[b]{2}{*}{ rrq } & r & $\leq 7$ & ru & التكرار & \multirow{2}{*}{ النقطر من لطلب } & \multirow[b]{2}{*}{19} \\
\hline & & & & & $\% \curlyvee \wedge, r$ & $\% r q, r$ & $\% r r, 0$ & $\%$ & & \\
\hline \multirow{2}{*}{11} & $\{0,01$ & . $\{\leqslant \leqslant$ & I rV & 17. & $V \varepsilon$ & $\varepsilon r$ & . & التكرار & أتمتع بشعبية & $r$. \\
\hline & $\%$ & $e^{2,2 N z}$ & & 1.6 & $\% \pi r, r$ & $\% r ч, \wedge$ & $\cdot$ & $\%$ & بين أفراد أسرتي & \\
\hline $\begin{array}{l}\text { أحياناً } \\
\text { (متو) } \\
\end{array}$ & $\begin{array}{c}T, 1 V \\
\%\end{array}$ & • & $1,9$. & & & & ف الاجتما. & & & \\
\hline
\end{tabular}

$$
\text { يوضح الجدول السابق: }
$$

ا. استجابات أفراد عينـة الدراسـة مـن أصـحاب المعاثــات منخفضـي الدخل حول التكيف

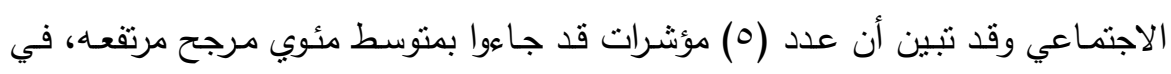

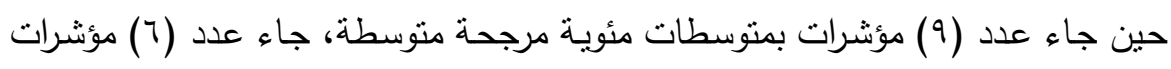
بمنوسطات مئوية مرجحة منخفضة.

r. كما أنه قد جاءت استجابات عينة الدراسة من أصحاب المعاثـات متفاوتة وقد كان ترتيب

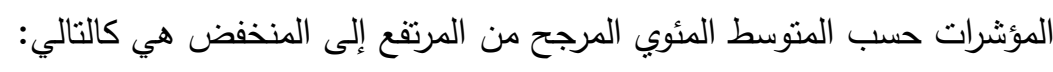

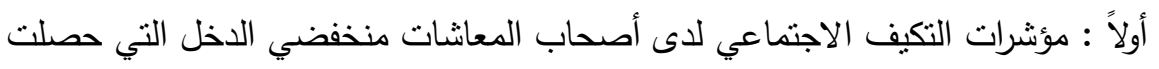

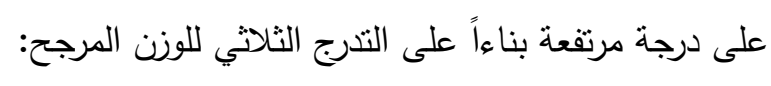

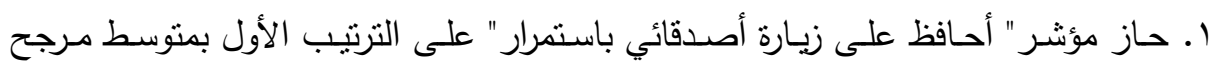

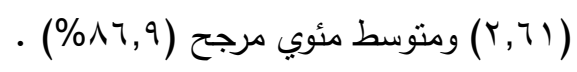


r. يليه مؤشر" علاقتلك بأقاربك وأسرتلك مستمرة" حصل على الترتيب الثناني بمنوسط مرجح

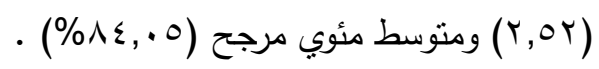

r. يليه مؤشر" أجد صعوبة في التواصل الاجتماعي مع أفراد لاأعرفهم" حصل على على الترتيب

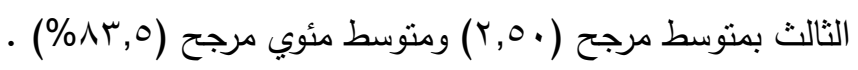

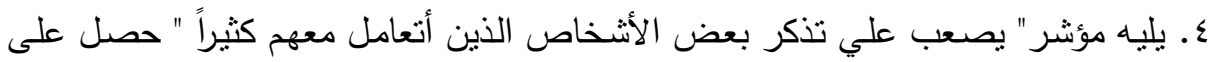

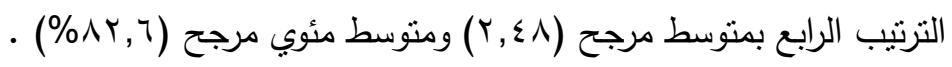

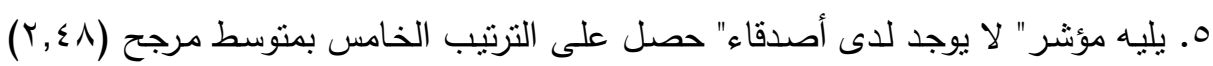

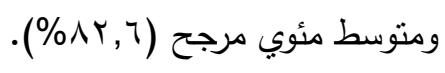

وقد تبين مما سبق وجود مؤشرات التكيف الاجتماعي لدى أصحاب المعانشات منخفضي

- اتفقت مع دراسة ( سهيل حسنين : ( . . ب) والمسنين أخبروا عن وجود علاقات جيدة مع أبنائهم. - اتفقت مع دراسة (نهى حامد، ه . . ب) أن المسنون الذين يعيشون مع أسرهم أثر توافقاً من المسنون الذين يقيمون فى دور الإيواء

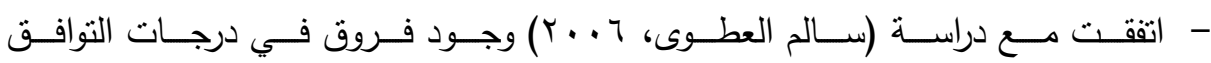
الانفعالي، والأسري، وتحقيق الذات، وتكوين الصداقات.

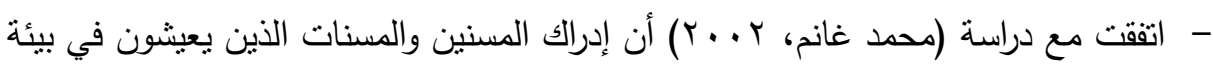
طبيعيـة للمساندة الاجتماعية أكبر وأفضل من المسنين والمسنات الذين يقيمون في دور

$$
\text { الإيواء. }
$$

- اتفقت مع دراسة (آمال جودة، 7 . . ب) وجود علاقة ارتباط سلبية دالة بين أساليب المواجهة الفعالة والوحدة النفسية.

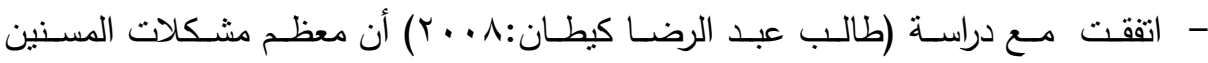
وأثندها هي إحساسهم بالعزلة عن المجتمع بعد اعتزالهم عنهم. 
- اتفقت مع دراسة (جولتان، وعطاف، ^ . . ب) المشكلات التي يعاني منها المسنون الفلسطينيون في محافظة غزة (المشاكل الاجتماعية الاقتصادية ، والمشكلات النفسية).

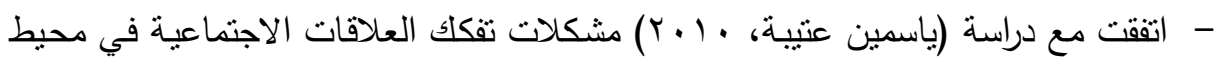

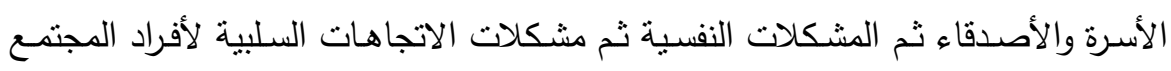
تجاه كبار السن.

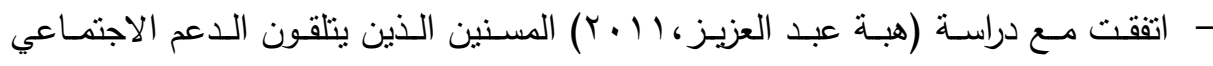

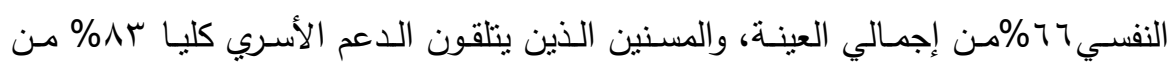
إجمالي العينة. - اتفقت مع دراسة (نجاة المرابط، با ـ ب) أهم المشكلات الاجتماعية التي تواجه المسنون في الريف هي عدم الاهتمام والعناية بهم من قبل أفراد أسرتهم.

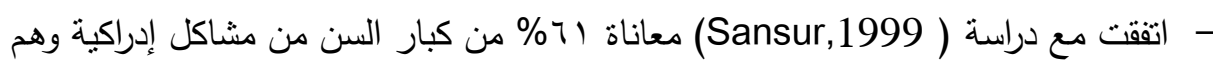

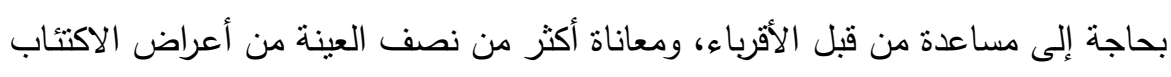
وتدهور في الصحة النفسية والعقلية.

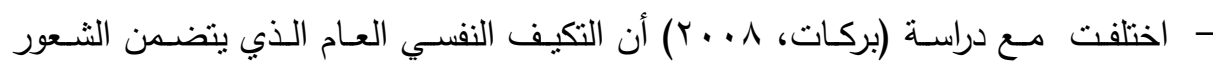

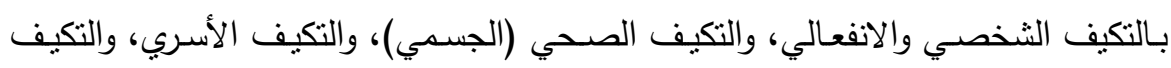

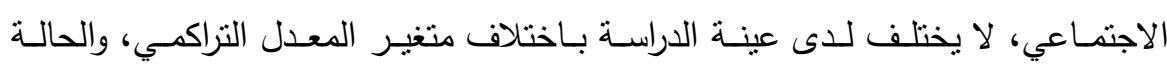
الاجتماعية، والحالة الاقتصادية.

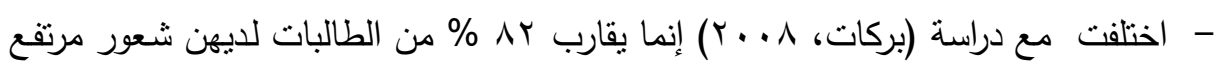
بالتكيف النفسي. - اختلفت مع دراسة ( سهيل حسنين : ( . . ب) المسنين يشاركون في المناسبات الاجتماعية. - اختلفت مع دراسة (نايف الحمد، خالد العوهلي، محمود حميدات: 2016) هناك علاقة عكسية دالة إحصائيا بين الرهاب الاجتماعي والتكيف النفسي والاجتماعي.

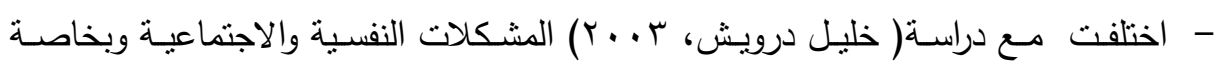
شعور المسنين بالحزن والكآبة الناجم عن تفكيرهم بأحفادهم وفقدانهم لمكانتهم في الأسرة

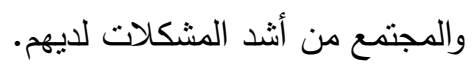


- وكذلك اتفقت مع النظرية البنائية الوظيفية حيث يشير البناء إلى العلاقات المستمرة والثابتة

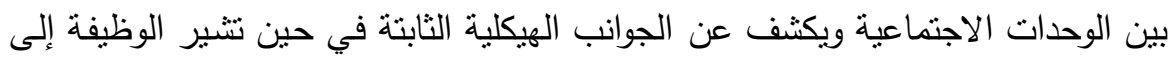

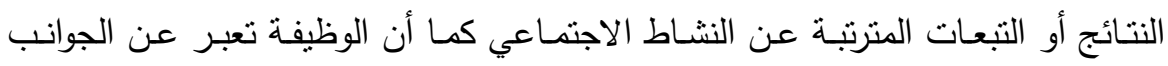

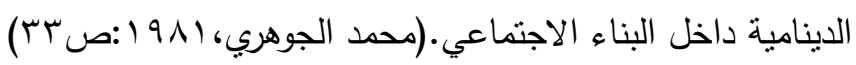

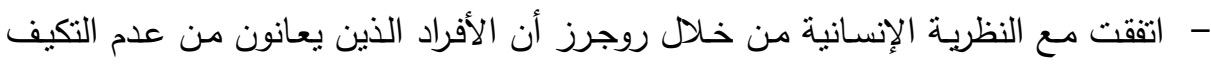

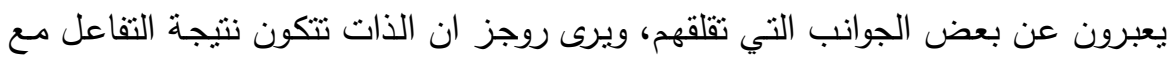

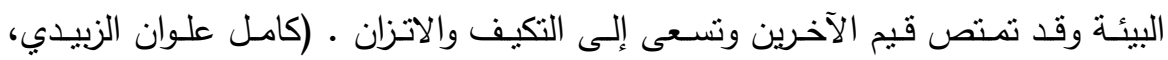

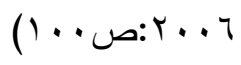

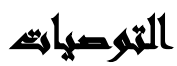

ا-حتى لا يصبح المسن عالة على أسرته وأقاربه يجب أن تهنم الدولة وخاصة الممسين الذين

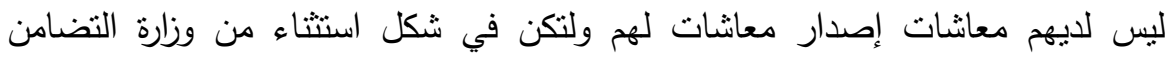
الاجتماعي وتكن تحت مسمى (حالات استثائية) تعينهم على سد احتياجاتهم الثخصية. r-التوسع والاهتمام بإنشاء دور لرعاية المسنين حتى تتكفل بالمسن الذي يعانى بعدم وجود مأوى له أو عدم اهتمام أولاده ورعايتهم لله.

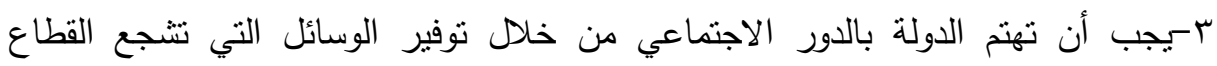

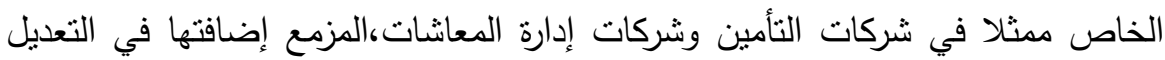
المقترح على قانون صناديق التأمين الخاصة، في أداء دورها ورعاية هؤلاء الفئة.

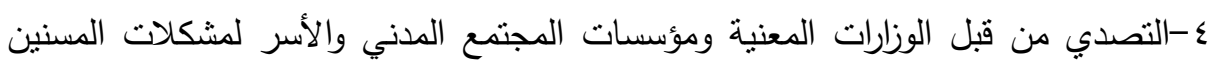
وتوفير الحلول العملية الملائمة لها.

\section{المرات}

أحمد زكي بدوي ( ( . ب): معجم مصطلحات العلوم الاجتماعية، طس، بيروت، مكتبة لبنان. أحمد زيد (عـ9 (1): علم الاجتماع بين الاتجاهات الكلاسيكية والنقدية، دار المعارف القاهرة 
أحمد عزت راجح (ب/91 )): أصول علم النفس، المكتب المصري الحديث، القاهرة. إسماعيل علي سعد: (990) الاتجاهات الحديثة في علم الاجتماع، دار المعرفة الجامعية، الإسكندرية.

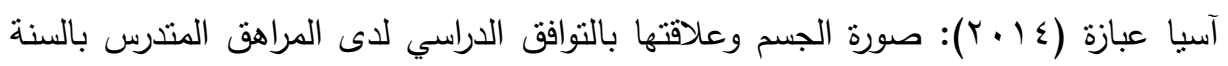

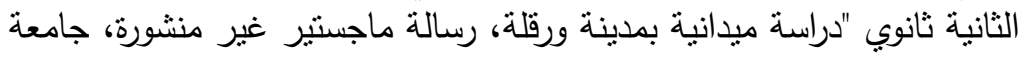
قاصدي مرياح ،الجزائر

جمال زكي، السيد يس(1971): أسس البحث الاجتماعي، دار الفكر العربي، القاهرة.

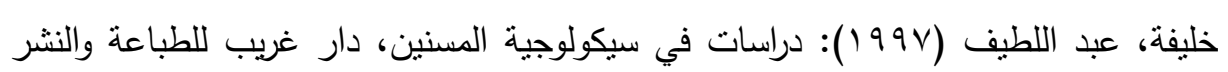
والتوزيع، القاهرة

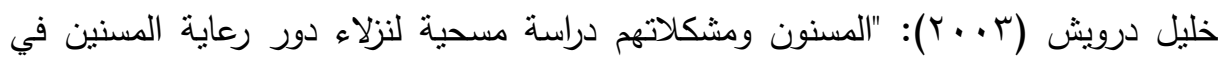

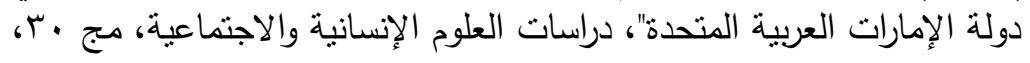

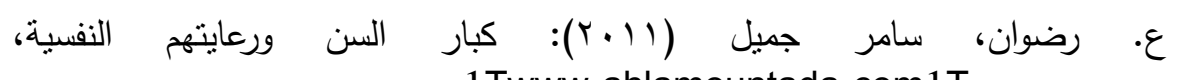
1Twww.ahlamountada.com1T

سلمى كو ندة (ب (ب): دور الخدمة الاجتماعية في تحقيق التكيف لدى المسنين في مراكز

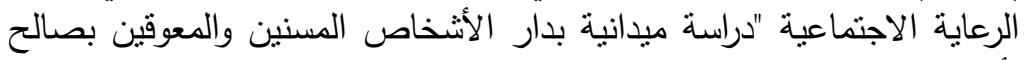

سمية جميل عوض (Y V P r): أثز برنامج تدريبي لمساعدة كبار السن في الأردن على التكيف

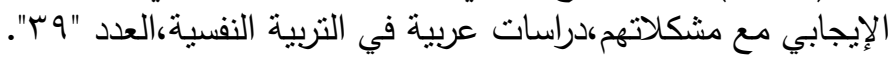

سهير كامل أحمد (991 (1)): دراسات في سيكولوجية المسنين. الإسكندرية. مركز الإسكندرية للكتاب

الثماع خليل محمد حسن، خضير كاظم حمود ( (... r): نظرية المنظمة، عمان.

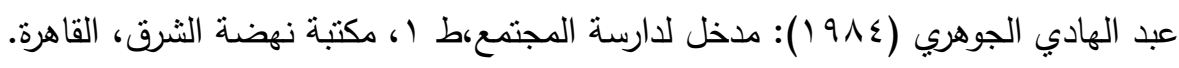

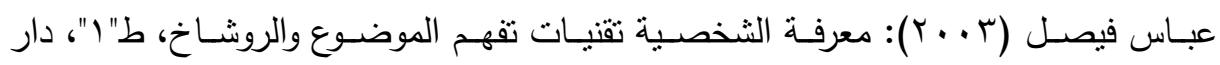

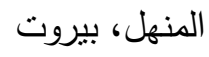

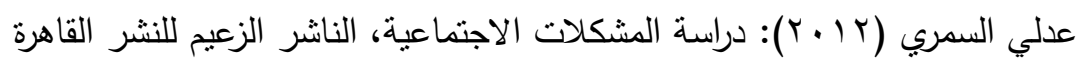

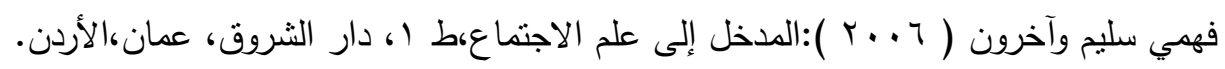

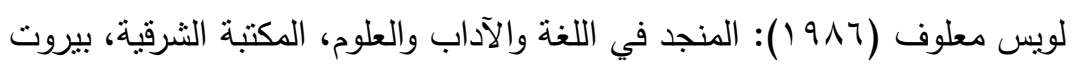




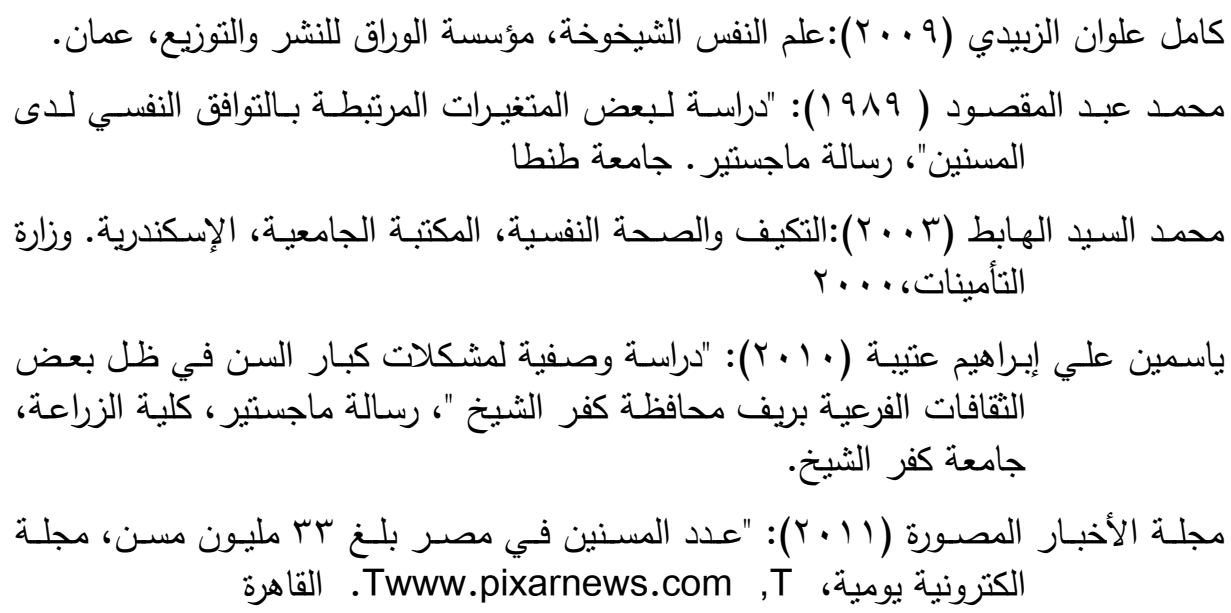

Alexopoulos, G.; Rane, P. and Arena, P. (2013). Problem -Solving versus supportive therapy in geriatric major depression with executive dysfunction, American Association for Geriatric

Psychiatry, retrieved from http://jap.psychiatryonline.org/misc/ term.html.

Rocher ,Guy (1981): Introduction à la sociologies générale: Le chan gement social, Tome3, Editions H.M.H, Paris.

Wolmen, B.B.(1973): Dictionary of Benavioural Science. New York Von no strand Reinnold Company. USA

Woodruff-Pak, S. (1997). The neuropsychology of aging, London: Black Publishers Ltd. 
آيه عبد المرضي وآخرون

\title{
SOCIAL AND PHYSICAL PROBLEMS RELATED TO THE LOW INCOME OF PENSIONERS AND THE MEANS OF SOCIAL, PSYCHOLOGICAL AND ENVIRONMENTAL ADJUSTME NT WITH THEM
}

\author{
Aya A. Rashid ${ }^{(1)}$; Samia S. khder $^{(2)}$; Ahmed F. Mandour ${ }^{(1)}$ \\ and Hanan E. Zedan ${ }^{(1)}$ \\ 1) Institute of Environmental Studies and Researches, Ain Shams \\ University 2) Faculty of Education, Ain Shams University 3) Facalty of \\ Commerce, Ain Shams University
}

\begin{abstract}
The objective of the study was to investigate the social and physical problems related to the low income of the pensioners and the means of social, psychological and environmental adjustment with them. "Identifying the social and physical problems of the low-income pensioners. Identifying the social, psychological and environmental adjustment methods for the pensioners. (58) Males (58) Females Use the descriptive approach and the methodology Social survey and tools Questionnaire form Questionnaire for social and physical problems Researchers' preparation, adaptation Meeting The results of the study were as follows: 1. There was a statistically significant inverse relationship at the level of (0.05) between the social problems and the pension value of low income pensioners.) Between the tribal application and the post-application of the experimental group in the psychological flexibility as a whole and all its dimensions (the ability to form social relations with others, the ability to control the emotions, the ability to make decisions and planning to solve problems) in favor of the application of dimension and life.

There is a statistically significant inverse relationship at the level of (0.01) between the physical problems and the pension value of low income pensioners.

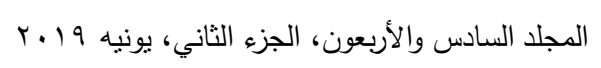


The results also indicated the level of social adjustment among low-income pensioners with an average weighted average (1.90) and weighted average $(63.17 \%)$ based on the three-fold weighted weight scale. This means that the level of social adjustment in the study sample (low-income pensioners).

\section{The study recommends:}

1. The attention of the officials of this segment through the provision of assistance and aid to them in various areas of life.

2. Addressing the concerned ministries, civil society organizations and families to the problems of the elderly and providing appropriate practical solutions.

Expansion and attention to the establishment of nursing homes for the elderly to take care of the elderly who suffer from lack of shelter or lack of interest and care for his childre

$$
\text { المجلد السادس والأربعون، الجزء الثاني، يونيه } 9 \text { 1 ـ ب }
$$

